\title{
Scaling wind stirring effects in an oceanic bulk mixed layer model with application to an OGCM of the tropical Pacific
}

\author{
Yuchao Zhu ${ }^{1,2} \cdot$ Rong-Hua Zhang ${ }^{1,2,3}$
}

Received: 8 June 2017 / Accepted: 22 October 2017 / Published online: 4 November 2017

(c) The Author(s) 2017. This article is an open access publication

\begin{abstract}
The mixed layer depth (MLD) plays an important role in the climate system through its influences on sea surface temperature (SST). The Kraus-Turner-Niiler (hereafter referred to as KTN) bulk mixed layer (ML) model is designed for describing the MLD and has been adopted widely by many ocean modeling. However, large biases exist in the MLD simulation using the original KTN model in the tropical Pacific. This is partly due to the uncertainties in representing wind stirring effect in the model, which is scaled by a parameter $\left(m_{0}\right)$. Traditionally, $m_{0}$ is taken as a constant uniformly in space. In this study, the $m_{0}$ is estimated as spatially and seasonally varying through its inverse calculation from a balance equation describing the turbulent kinetic energy (TKE) budget of the ML. It is illustrated that the $m_{0}$ is spatially varying over the tropical Pacific. The derived $m_{0}$ fields are then embedded into an ocean general circulation model (OGCM). Compared with the observations and the global ocean data assimilation system (GODAS) analyses, the MLD simulations in the OGCM with varying $m_{0}$ are substantially improved in the tropical Pacific Ocean on seasonal and interannual time scales. Additionally, the Pacific subtropical cells (STCs) become intensified, accompanied with the strengthening of upwelling in the eastern equatorial Pacific; thus, more realistic simulations are obtained in spatially and seasonally varying $m_{0}$ case compared with
\end{abstract}

Rong-Hua Zhang

rzhang@qdio.ac.cn

1 Key Laboratory of Ocean Circulation and Waves, Institute of Oceanology, Chinese Academy of Sciences, Qingdao 266071, China

2 University of Chinese Academy of Sciences, Beijing, China

3 Qingdao National Laboratory for Marine Science and Technology, Qingdao, China the constant $m_{0}$ case. As the related cooling effect from the upwelling is enhanced, the simulated SST is slightly cooled down in the eastern equatorial Pacific. Further applications and implications are also discussed.

Keywords Bulk mixed layer - Optimizing wind stirring effect $\cdot$ Ocean circulation models

\section{Introduction}

The sea surface temperature (SST) plays an important role in the climate system by governing the exchange of energy and mass between the ocean and atmosphere. In particular, the SST over the tropical Pacific has significant effects on seasonal to interannual climate variability worldwide (e.g., Cane and Zebiak 1985; Barnett et al. 1993; Zhang and Levitus 1996; Goddard et al. 2001; Zhu et al. 2015). Various models have been developed to better simulate the variability of SST, but large systematic biases remain in the many state-of-the-art models. One of the largest uncertainties in SST modeling is related to the parameterization of the vertical mixing processes in the upper ocean. Generally, there are two categories of such parameterizations: one is based on the turbulent closure models to estimate the vertical mixing coefficients (the coefficient-based approach; e.g., Mellor and Yamada 1982; Large et al. 1994); the second is to treat the uppermost layer as being well mixed, with its depth being determined by a bulk ML model (the bulk ML-based approach). The coefficientbased approach is usually adopted in level ocean models whereas the bulk ML-based approach is often used in the layer ocean models. A hybrid approach is also formulated. For example, the bulk ML model has been embedded into level OGCMs. Sterl and Kattenberg (1994) embedded a 
ML model into a $z$-coordinate OGCM for the Atlantic Ocean, and demonstrated a significant improvement for the upper ocean simulation. Different from the traditional coefficient-based vertical mixing approach by which the wind momentum is transferred into deeper ocean layer by layer as represented by vertical mixing processes, Zhang and Zebiak (2002) implicitly embedded a ML model into the Geophysical Fluid Dynamics Laboratory (GFDL) modular ocean model (MOM 3 ) and assumed that the wind stress, as a body force, is applied over the entire ML. As a result, wind momentum in the bulk ML-based approach can be more effectively transmitted over the entire ML compared with the coefficient-based approach. Their results demonstrated that a more realistic simulation can be achieved for the thermal and current structures in the tropical Pacific.

Previously, Kraus and Turner (1967) and Niiler and Kraus (1977) proposed a bulk ML model (hereafter referred to as KTN), which determines the MLD and its variation by integrating the turbulence kinetic energy (TKE) equation over the ML and assuming that a constant fraction of TKE produced by wind stirring is dissipated; TKE is defined as the mean kinetic energy per unit mass associated with turbulent eddies. In this formulation, the MLD is primarily determined by the local atmospheric forcing, including surface wind, heat flux, evaporation and precipitation (Lee et al. 2015; Yoshikawa 2015; Pookkandy et al. 2016). Meanwhile, the stratification at the base of ML also plays a critical role at the deepening phase of the ML (Pollard et al. 1972; Kang et al. 2010). It is notable that wind stirring is the major factor in the KTN model and the related TKE production is formulated as $2 m_{0} u_{*}^{3}$, a term representing direct wind stirring effects on the ocean.

Large uncertainties exist in appropriately determining the wind stirring effects in the ML dynamics as represented by the coefficient $m_{0}$. Laboratory experiments conducted by Kato and Phillips (1969) suggested $m_{0}=1.25$. By analyzing the data from the Woods Holes Oceanographic Institute IMET mooring deployed at $\left(1^{\circ} 45^{\prime} \mathrm{S}\right.$, $156^{\circ} \mathrm{E}$ ), Davis et al. (1981) found that the values for $m_{0}$ earlier were considerably large and suggested $m_{0}=0.4$. Using a one-dimensional model, Martin (1985) took this value and simulated the MLD and SST evolution at Ocean Weather Station (OWS) Papa $\left(50^{\circ} \mathrm{N}, 145^{\circ} \mathrm{W}\right)$, but found that the $m_{0}$ needs to be readjusted when the geographic location is changed and the $m_{0}$ used for a ML deepening case should be smaller than that used for a ML shoaling case. A similar result at OWS Papa was also documented by Acreman and Jeffery (2007). They found that $m_{0}=0.1-0.2$ in March-May and October-December when the ML is deep, and $m_{0}=0.2-0.35$ in June-September when the ML is shallow. All these results indicate that MLD simulations using the bulk ML model are sensitively dependent on $m_{0}$, which should be considered as spatially and seasonally varying.

In order to obtain the varying $m_{0}$ fields, long-term continuous observations for the upper ocean thermohaline structure are of great importance. However, due to the scarcity of simultaneous meteorological and oceanic observations, the estimate of $m_{0}$ is rather subjective. The $m_{0}$ is often manually prescribed in modeling the MLD and it is only validated at a few scattered stations. The values estimated in one location for realistically modeling the MLD are practically inadequate for uses in other regions. It is desirable to estimate the $m_{0}$ in an objective and optimal way in the sense that the best possible observed MLD can be depicted. As the basinwide data from Argo floats have become available over the past decade, the time series of temperature and salinity profiles provide an opportunity to estimate the MLD at basinwide scale, which can be used to validate the ML model and optimize the model empirical parameters including $m_{0}$ which, in turn, can be used to produce the observed MLD more realistically.

In this study, we propose an inverse method to optimally estimate the $m_{0}$ based on the KTN bulk model equation. More specifically, the parameter $m_{0}$ is estimated through its inverse calculation from the KTN bulk equation describing the MLD and its variation, Argo dataset and meteorological reanalysis data. In this method, for a given MLD, the atmospheric forcing fields are calculated from the reanalysis dataset and are introduced to the KTN equation, being able to yield an optimized estimate of $m_{0}$ by balancing various terms in the equation. The optimized $m_{0}$ is then adopted into an OGCM-based simulation for the tropical Pacific Ocean in an attempt to better simulate the MLD. The improved MLD simulations are expected to affect the simulations of other fields in the ocean, including currents and SST.

The paper is organized as follows. Section 2 describes the model and some datasets used in this study. Section 3 demonstrates the spatial structure of $m_{0}$ calculated from the inverse method in the tropical Pacific. Using the optimized $m_{0}$, the improved model performance is given in Sect. 4 . Finally, we provide the possible explanations for the relationships among the $m_{0}$, MLD and the externally specified wind forcing in Sect. 5 and summarize our results in Sect. 6, respectively.

\section{Model description and dataset}

The MLD is determined by various factors which influence the TKE budget within the ML. During winter, for instance, the TKE generated by surface cooling and more energetic wind stirring exceeds the potential energy required to lift the denser water below and, as a consequence, the ML deepens. During summer, the TKE input by wind is not sufficient 
enough to remove the stratification generated by the stabilizing buoyancy flux, and the ML retreats to a shallow depth. These processes can be described by a bulk ML model (e.g., Kraus and Turner 1967; Niiler and Kraus 1977).

\subsection{The inverse calculation of $\mathbf{m}_{0}$}

The MLD and its variation are described by the KTN model representing an energy balance between the TKE input and the potential energy required to entrain the water below as

$$
\begin{aligned}
\Delta b w_{e} h= & 2 m_{0} u_{*}^{3}+\frac{\left[(1+n) B_{0}-(1-n)\left|B_{0}\right|\right] h}{2}, \\
& +J_{0}\left[h\left(1+e^{-h / h_{p}}\right)-2 h_{p}\left(1-e^{-h / h_{p}}\right)\right]
\end{aligned},
$$

where $\Delta b$ represents the change of buoyancy across the base of ML, $w_{e}$ is the entrainment velocity, $h$ is the MLD, $u_{*}$ is the surface friction velocity, $B_{0}$ and $J_{0}$ are the non-penetrating and penetrating component of the upward surface buoyancy flux, $h_{p}$ is the attenuation depth of the shortwave radiation (Zhang et al. 2011), $m_{0}$ and $n$ need to be determined adequately so that the model can produce corresponding observations.

The term on the left-hand side of Eq. (1) represents the potential energy required to lift the dense water and mix it through the ML under the condition of entrainment; it becomes zero when detrainment occurs. The first term on the right-hand side represents the production of TKE by wind stirring, which is proportional to the cube of the sea surface friction velocity. The second term represents the TKE changes induced by the non-penetrating surface buoyancy flux (the sum of longwave radiation flux, latent heat flux, sensible heat flux and $\sim 67 \%$ shortwave radiation flux); it is a production term only when the buoyancy is destabilizing $\left(B_{0}>0\right)$. The effect of the penetrating component $(\sim 33 \%$ shortwave radiation flux) is presented by the third term and it is generally negative.

Numerous studies deal with the identification of the two empirical parameters $m_{0}$ and $n$. The parameter $n$ represents the ratio of the entrainment buoyancy flux to the surface buoyancy flux when convection occurs and the parameter $m_{0}$ scales the rate of TKE input by wind stirring. In general, the values of $n$ deduced from the observations, the laboratory experiments and the large eddy simulations (LES) are relatively consistent and in close agreement with the choice: $n=0.18$ (Heidt 1977; Davis et al. 1981; Wang 2003; Noh et al. 2010). However, the estimates of $m_{0}$, as mentioned above, are largely scattered and it is difficult to compare among the different published values (Gaspar 1988). Thus, it is desirable to estimate the $m_{0}$ in an objective and optimal way in the sense that the best possible observed MLD can be depicted.
A novel approach is suggested in this paper to optimally estimate $m_{0}$ through its inverse calculation from the KTN bulk equation, Argo dataset and meteorological reanalysis data. The inverse calculation is performed by using the Eq. (1). Variables associated with the surface momentum, heat and freshwater fluxes can be calculated using the atmospheric reanalysis datasets; the $h_{p}$ can be derived from the ocean color data; the Argo data are used to estimate the MLD and the buoyancy jump at the base of the ML. When all these fields are given, the parameter $m_{0}$ can be determined directly from the equation. The estimated $m_{0}$ field is an optimized one in the sense that the best possible observed MLD can be depicted when the estimated $m_{0}$ is, in turn, adopted to determine MLD using the equation. Note that $n$ is assigned to be 0.18 in accordance with the recent LES results (Wang 2003; Noh et al. 2010). Next, we will introduce the datasets used for the inverse method and exhibit the fields of the variables in Eq. (1).

\subsection{Datasets used}

The National Centers for Environmental Prediction/National Center for Atmospheric Research (NCEP/NCAR) monthly reanalysis dataset, including wind stress, shortwave radiation and precipitation (Kalnay et al. 1996), are used to calculate the variables associated with the atmospheric forcing fields. The friction velocity is calculated by $u_{*}=\sqrt{\tau / \rho}$ for surface wind stress $\tau$ and water density $\rho$. The $u_{*}$ fields can also be calculated from the daily wind stress fields before the monthly averages are carried out, which will make a difference in the regions where the short term variations in wind directions are frequent. But in the tropical Pacific Ocean, the trade winds are prevailing and the differences are not substantial enough to influence our results. Thus, in this study, the monthly $u_{*}$ fields are calculated from the monthly wind stress fields and the method is commonly employed in the previous studies (e.g., Lee et al. 2015; Pookkandy et al. 2016). Figure 1a illustrates the annual-mean $u_{*}$ over the tropical Pacific, which is weak in the western equatorial Pacific and the eastern equatorial upwelling regions, but is strong with values exceeding $8 \times 10^{-3} \mathrm{~ms}^{-1}$ in the areas where the trade winds are prevailing. The surface buoyancy flux is calculated by $B_{0}=\left(\alpha g / \rho c_{p}\right) Q_{0}+\beta g S_{0}(E-P)$, where $Q_{0}$ is the non-penetrating component of the surface heat flux, $E-P$ (evaporation minus precipitation rate) is the net surface freshwater flux, $S_{0}$ is the surface salinity, and $c_{p}$ is the heat capacity of seawater, and $\alpha$ and $\beta$ are the thermal and haline coefficients of expansion, respectively. The penetrating component of the buoyancy flux is calculated by $J_{0}=\left(\alpha g / \rho c_{p}\right) \gamma R_{s}$, in which $R_{s}$ is the shortwave radiation, $\gamma$ is the fraction of the shortwave radiation that is able to penetrate beyond the upper a fewer meter of the ocean, and is assigned 0.33 according to the recent studies (Murtugudde 
Fig. 1 The horizontal distributions of annual-mean fields for (a) the friction velocity, (b) the non-penetrating and (c) the penetrating components of the surface buoyancy flux. The contour interval is $10^{-3} \mathrm{~ms}^{-1}$ in (a), $2 \times 10^{-8} \mathrm{~m}^{2} \mathrm{~s}^{-3}$ in (b) and $0.25 \times 10^{-8} \mathrm{~m}^{2} \mathrm{~s}^{-3}$ in (c) (a) U.

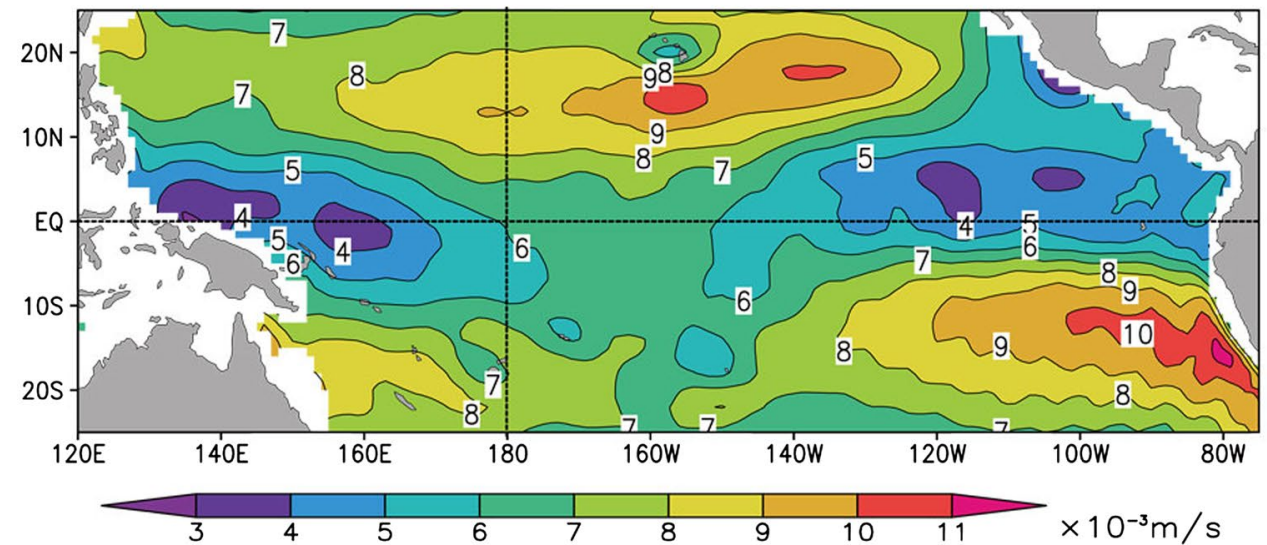

(b) $\mathrm{B}_{0}$

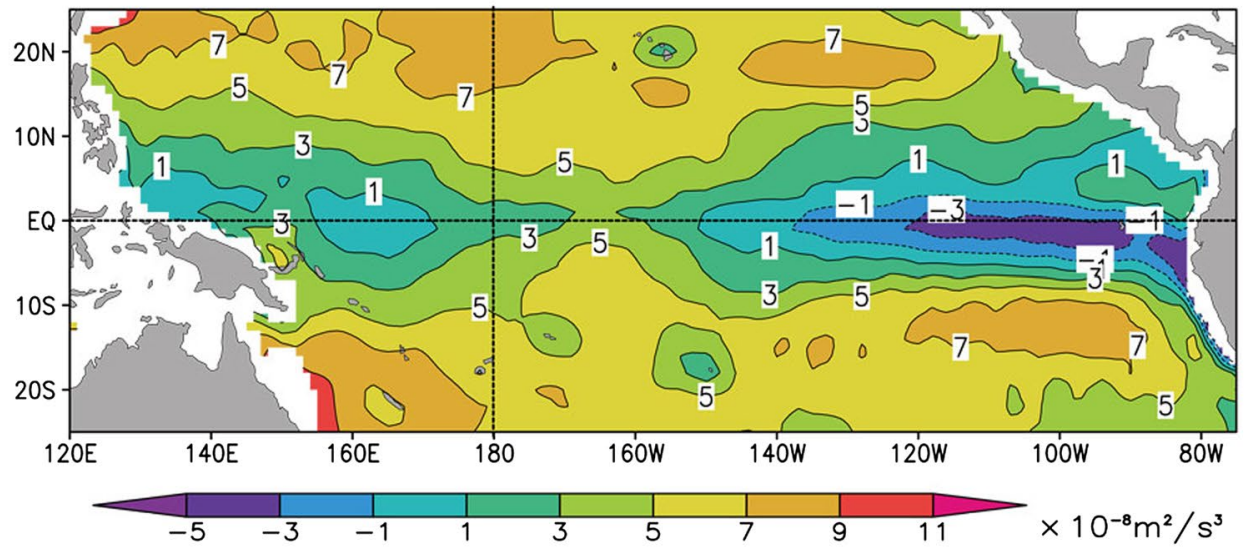

(c) $\mathrm{J}_{0}$

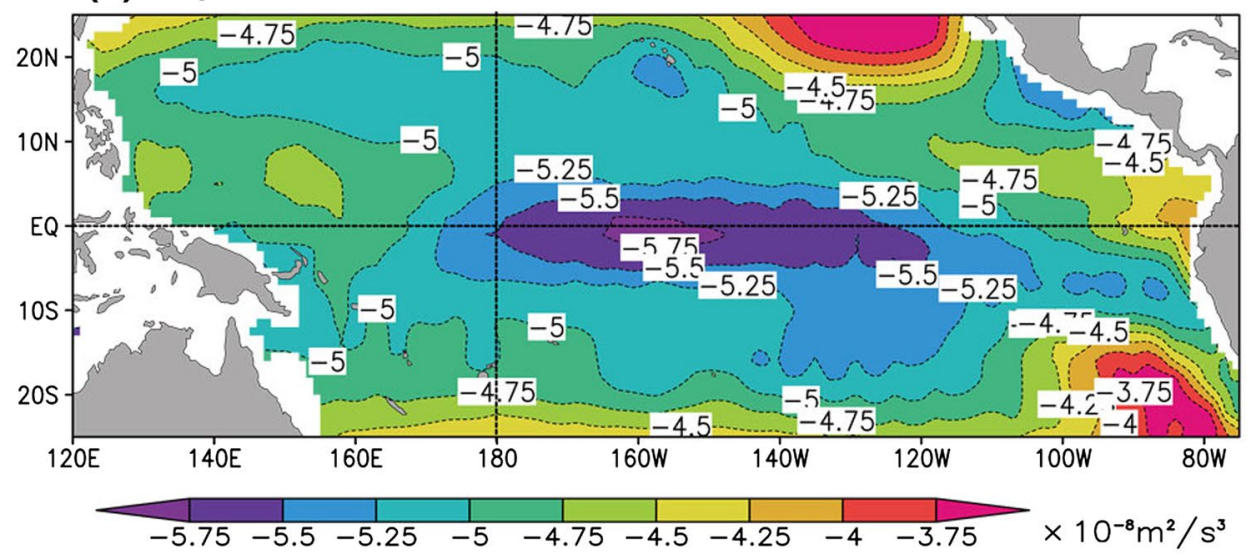

et al. 2002; Zhang et al. 2011). Note that the component of $Q_{0}$ associated with long wave radiation, latent heat flux and sensible heat flux is obtained from the OGCM using the simplified bulk formula of Seager et al. (1988), rather than directly from the NCEP/NCAR reanalysis datasets. We choose this approach in an attempt to improve the MLD simulation as realistic as possible because this bulk formula is embedded into the OGCM tested in this study. Figure $1 \mathrm{~b}$ illustrates the annual-mean field for $B_{0}$, which is positive when the ocean is losing buoyancy. Due to the net heating influx into the ocean, high buoyancy gain is found in the eastern equatorial Pacific. Large buoyancy losses occur in the subtropical regions and off the coast of Peru owing to the effects both by the annual-averaged surface cooling and by the vigorous evaporation.

The attenuation depth of shortwave radiation is indicated by $h_{p}$ in Eq. (1). Because of the pure water, dissolved and suspended matter, vertical distribution of the penetrating solar radiation (Fig. 1c) is formulated by an exponentially attenuated with depth and the $h_{p}$ essentially represents the 
$e$-folding depth. This depth can be significantly affected by marine ecosystem and can be derived from the chlorophyll (Chl) content data which are difficult for in-situ observations at the basin scale. The development of the remote sensing techniques makes satellite-based ocean color data available and the effects of the penetrative radiation on the upper ocean state are reported by the recent studies (Murtugudde et al. 2002; Zhang 2015). In this study, merged monthly Chl fields from the GlobColour product (http://globcolour.info), which is developed, validated, and distributed by ACRI-ST, France (Maritorena et al. 2010), are used to calculate the fields of $h_{p}$ following the method proposed by Murtugudde et al. (2002) and Zhang et al. (2011):

$h_{p}(x, y)^{-1}=K_{p}(x, y)=K_{w}+a \cdot \operatorname{Chl}(x, y)^{b}$,

in which $K_{w}=0.027 \mathrm{~m}^{-1}, a=0.0518 \mathrm{~m}^{-1} /\left(\mathrm{mg} \mathrm{m}^{-3}\right)$, and $b=0.428$. Figure 2 shows the annual-mean structure of the derived $h_{p}$ field in the tropical Pacific. Values less than $18 \mathrm{~m}$ are found in the coastal and equatorial upwelling regions corresponding to the high $\mathrm{Chl}$ concentration. Large values are found in the subtropical regions, where the seawater is relatively oligotrophic.

The Argo dataset is provided by the International Pacific Research Center (IPRC)/Asia-Pacific Data-Research Center (APDRC) for calculating the other variables in Eq. (1). This product includes the MLD and three-dimensional gridded fields for temperature and salinity with a $1^{\circ}$ horizontal resolution at the standard depths. The MLD is defined as the depth at which the density increases from $10 \mathrm{~m}$ to the value equivalent to the temperature drop of $0.2{ }^{\circ} \mathrm{C}$. We take this definition because it represents the depth to which the turbulent mixing penetrates, being suitable for the validation of one-dimensional bulk ML models (Kara et al. 2000). Annual-mean structure of the observed MLD is shown in Fig. 3. Due to the weak surface friction velocity (Fig. 1a) and the stabilizing surface buoyancy flux (Fig. 1b), the ML is relatively shallow $(<30 \mathrm{~m})$ in the both sides of the equator in the tropical Pacific and the intertropical convergence zone (ITCZ). Values larger than $50 \mathrm{~m}$ are found in the regions with the energetic surface wind and the strong surface buoyancy losses. Notable exception is found in the
Fig. 2 The horizontal distributions of annual-mean $h_{p}$ field for the tropical Pacific. The contour interval is $2 \mathrm{~m}$
Fig. 3 The horizontal distributions of annual-mean MLD from the IPRC/APDRC products. The contour interval is $5 \mathrm{~m}$
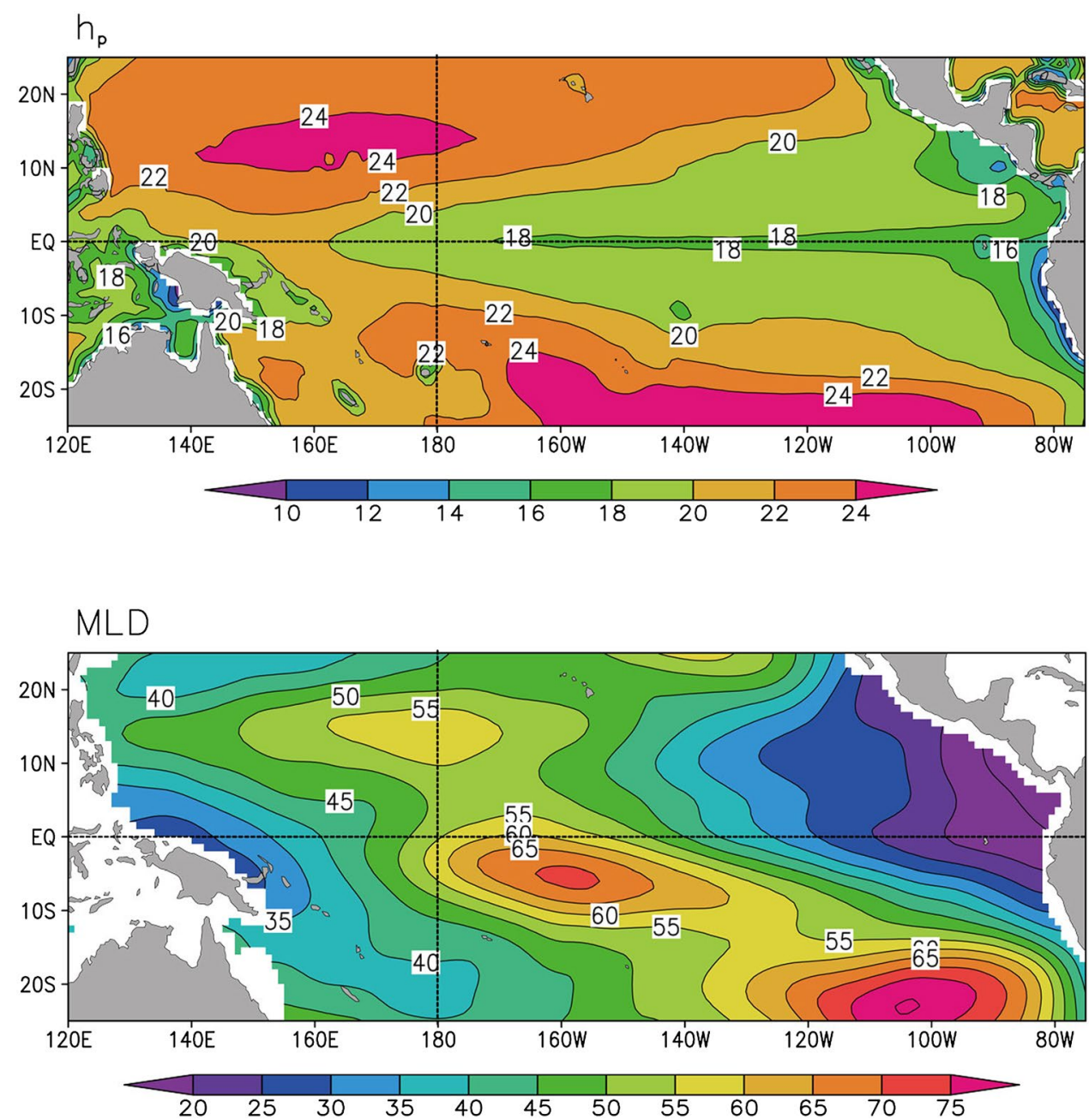
south-central equatorial Pacific where the weak wind stress and the moderate surface buoyancy losses cannot maintain the unusually deep ML. Results from the in-situ observation show that an enhanced turbulent mixing with the dissipation rate exceeding $10^{-7} \mathrm{~W} \mathrm{~kg}^{-1}$ reaches $100 \mathrm{db}$, but the exact generation mechanisms remain unclear (Cheng and Kitade 2014). In our analysis, the ML tendency is equal to the entrainment rate $w_{e}$ for the 1-D model; it is calculated as $\partial h / \partial t=d h / d t-w_{e k}$, where $w_{e k}$ is the Ekman pumping/ suction velocity calculated using the wind stress fields, and $d h / d t$ is the time-derivative of MLD calculated using the Argo data.

To assess the improved performance in the current simulations, outputs from the NCEP Global Ocean Data Assimilation System (GODAS; available online at http:// www.esrl.noaa.gov/psd/) are used. The ocean model in this system is based on the GFDL MOM 3, which is forced by the atmospheric forcing fields from the NCEP reanalysis 2. GODAS has a horizontal resolution of $1^{\circ} \times 1^{\circ}$, which is enhanced to $1 / 3^{\circ}$ in the meridional direction between $10^{\circ} \mathrm{S}$ and $10^{\circ} \mathrm{N}$; it has 40 levels in the vertical with a $10 \mathrm{~m}$ resolution in the upper $200 \mathrm{~m}$. Some observed datasets are assimilated through a three-dimensional variational assimilation (3DVAR) method. It is demonstrated that the ocean meridional currents in GODAS have amplitudes comparable to the observations, but large biases still exist in the zonal currents (Huang et al. 2010). Thus, zonal current sections on the equator from Johnson et al. (2002) are additionally employed for model validation. It is based on the direct measurements of the upper ocean currents from 172 synoptic sections, most of which are from the Tropical Atmosphere Ocean (TAO) mooring arrays.

The domain of our analyses and OGCM-based simulations cover the tropical Pacific Ocean from $120^{\circ} \mathrm{E}$ to $75^{\circ} \mathrm{W}$ and from $25^{\circ} \mathrm{S}$ to $25^{\circ} \mathrm{N}$ with a resolution of $1^{\circ} \times 0.5^{\circ}$, and datasets with the different resolutions are remapped to the analysis grid in advance. Analysis period spans from January 2005 to December 2015 in consideration of the scarcity of the Argo observations before.

\subsection{The OGCM and experiments}

The OGCM, which is developed by Gent and Cane (1989) for the tropical Pacific Ocean, is based on the primitive equation model with the reduced gravity approximation. The uppermost layer represents the oceanic ML and the water column below is vertically divided into a number of layers according to the prescribed ratio. Therefore, once the MLD is predicted by the ML model, the thickness of the remaining layers can be calculated diagnostically. A mixing scheme combining the KTN ML model with Price's dynamical instability model (Price et al. 1986) has been embedded into the OGCM used in our study (Chen et al. 1994a).
Murtugudde et al. (1996) coupled the OGCM to an advective atmospheric mixed layer (AML) model to estimate sea surface heat fluxes and showed the nonlocal effects of the atmospheric boundary layer on SST. The OGCM covers the tropical Pacific from $120^{\circ} \mathrm{E}$ to $76^{\circ} \mathrm{W}$ and from $25^{\circ} \mathrm{S}$ to $25^{\circ} \mathrm{N}$ with a horizontal resolution of $1^{\circ}$ longitude by $0.5^{\circ}$ latitude, and 31 layers in the vertical direction. Near the southern and northern boundaries, sponge layers are introduced for relaxing the model temperature and salinity fields to the observational data from World Ocean Atlas 2001 (WOA01). More model details can be found in Zhang et al. $(2006,2015)$. The OGCM is initiated from the WOA01 salinity and temperature fields and is integrated for 50 years using atmospheric climatological forcing fields, including the solar radiation, precipitation and wind stress from the NCEP/NCAR reanalysis product.

To access the effects of the optimized $m_{0}$ on the simulations, two experiments are performed: one is denoted as a control run (hereafter referred to as CTL run), in which $m_{0}$ is assigned 1.25 over the model domain; another is a sensitivity run in which the seasonally and spatially varying fields of $m_{0}$ are taken (hereafter referred to as SV run). Two simulations are conducted from January 1963 through December 2015, which is forced by the atmospheric fields from the NCEP/ NCAR reanalysis datasets. Mean fields for currents and SST are calculated by averaging the entire simulation periods, but those for MLD are calculated by averaging the simulation periods from 2005 to 2015 during which the observed MLD fields are available.

\section{The structure of $m_{0}$ in the tropical Pacific}

The inverse method is applied separately for each month, yielding 12 seasonally varying $m_{0}$ fields. The $m_{0}$ is depicted as spatially and seasonally varying and its space-time varying characteristics structure is shown in this section.

Figure 4a demonstrates the spatial pattern of the annually averaged $m_{0}$ in the tropical Pacific. Corresponding to the deep ML regions, two patches with the elevated values exceeding 2.0 are found in the central equatorial Pacific and the subtropical southeastern Pacific. Off the coast of Australia, Mexico and Peru, the values of $m_{0}$ are relatively small and are similar with the values $(\sim 0.4)$ used in the previous studies (Davis et al. 1981; Chen et al. 1994a). Meanwhile, the seasonal cycle of the estimated $m_{0}$ (Fig. 4b) shows that $m_{0}$ is seasonally dependent with the value used for ML deepening being smaller than that used for shoaling, which is consistent with the results from Martin (1985) and Acreman and Jeffery (2007).

The $m_{0}$ pattern is consistent with our current understanding of the ML dynamics and other previous studies. Several factors exert influences on the MLD, including the wind 
Fig. 4 a The spatial pattern for the annually averaged $m_{0}$ in the tropical Pacific and $\mathbf{b}$ the seasonal cycle of the estimated $m_{0}$ and MLD averaged over the regions north of $5^{\circ} \mathrm{N}$

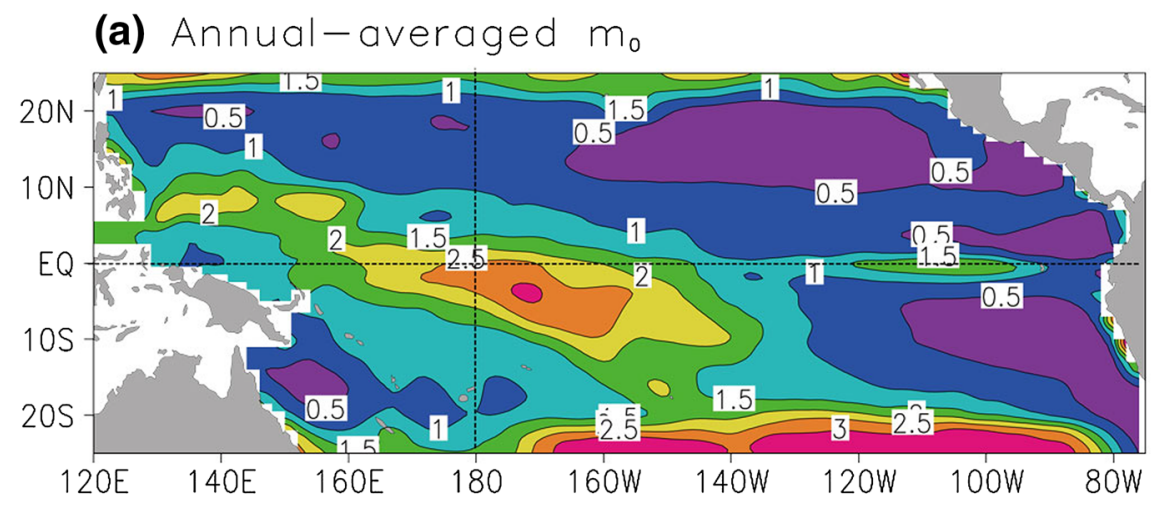

(b) Seasonal cycle of the $m_{0}$

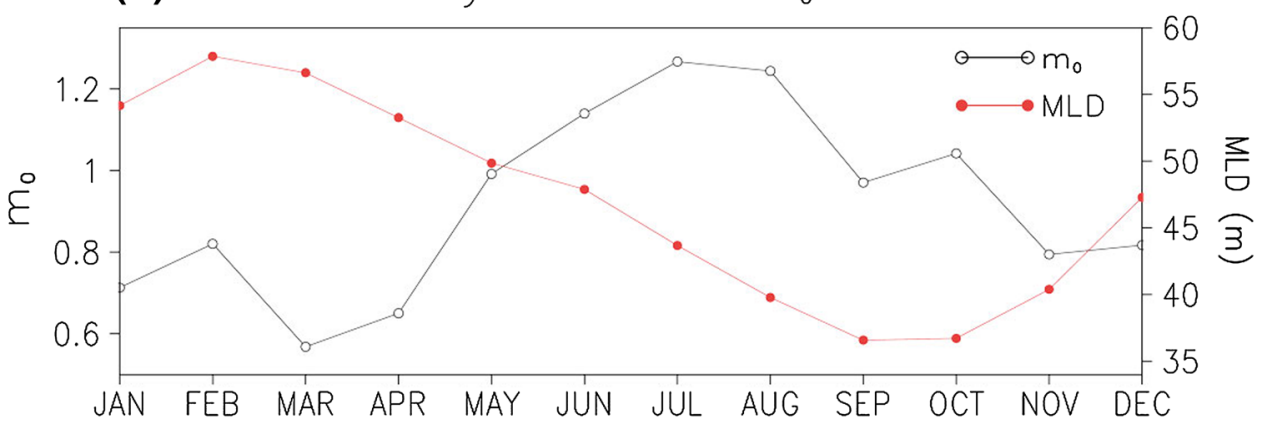

stirring effects and the Coriolis force effects (Goh and Noh 2013). In the equatorial ocean, the deep Ekman layer contributes to the unimpeded downward propagation of heat and momentum, giving rise to a very deep ML. Therefore, a relatively large $m_{0}$ value is required to simulate the MLD that is in resemblance with observations for the equatorial regions. Indeed, tests of the KTN model are conducted by Godfrey and Schiller (1997) using the IMET mooring dataset, which was observed at $\left(1^{\circ} 45^{\prime} \mathrm{S}, 156^{\circ} \mathrm{E}\right)$. Their study revealed that the simulated MLD is consistently shallower than the observed when taking $m_{0}=0.4$, which implies that a larger $m_{0}$ is favorable for the equatorial ocean. Another region with the large $m_{0}$ is in the subtropical southeastern Pacific where the horizontal density advection plays an important role in the seasonal deepening of the ML (Liu and Lu 2016). Although the horizontal derivatives are neglected in the mathematical derivation for the one-dimensional ML model, it is worth noting that the horizontal advection can modify the stratification of the upper ocean, which determines the potential energy required to entrain the denser water into the pycnocline. In our analysis, buoyancy jump across the base of ML is calculated from the Argo data and the effects of stratification are implicitly considered when calculating the left-hand side of Eq. (1).

The lateral ocean dynamics play a critical role in the formation of ML in the tropics (Lorbacher et al. 2006;
Pookkandy et al. 2016), which is neglected in the onedimensional ML model. In addition, uncertainties in parameterizing the dissipation rate also result in considerable biases (The KTN model assumes that a constant fraction of TKE produced by wind stirring is dissipated). Although a one-dimensional ML model can be tuned well to fit the observation (usually the in-situ observations at OWS Papa), systematic biases exist in the simulations when it is implemented into a three-dimensional OGCM. Until the dynamics of the ML are well understood, a practical way is to use the justified empirical parameters to compensate for the missing and misrepresented physical processes. As revealed in Fig. 4a, regions with large $m_{0}$ correspond to those in the weak $u_{*}$, which indicates that the method we proposed here can be viewed as a compensation for the TKE budget, readjusting the term $2 m_{0} u_{*}^{3}$ to achieve the balance with the other terms including buoyancy flux.

Another reason for this choice is that two types of MLD responses to $u_{*}$ can be found in the tropics at the monthly time scale (see Sect. 5 for details). The existing length scales characterizing the MLD are far from desirable to match with the observations despite the inclusion of Earth's rotation effect. These issues will be discussed in more detail in Sect. 5. But for now, OGCM simulations with the optimized $m_{0}$ are shown in the following section. 


\section{The effects on the OGCM-embedded simulations}

\subsection{An improved MLD simulation}

Figure 5 illustrates the annual-mean MLD field simulated from the CTL run and the SV run. Compared with that estimated from the Argo data (Fig. 3), the MLD is poorly simulated in the CTL run. A substantial overestimation arises in the northern tropical Pacific and the southeastern tropical Pacific. In particular, the simulated MLD exceeds $85 \mathrm{~m}$ in the northeastern basin whereas the observed is shallower than $45 \mathrm{~m}$. These biases can be reduced somewhat with $m_{0}=0.4$, but it is evident that the relatively deep ML in the central Pacific south of the equator cannot be reproduced with the spatially uniform values of $m_{0}$. When using the varying fields of $m_{0}$, significant improvements are evident (Fig. 5b). A substantial reduction in the MLD biases by more
Fig. 5 Annual-mean MLD simulated in (a) the CTL run, (b) the SV run, and (c) their differences (the SV run minus the CTL run). The contour interval is $5 \mathrm{~m}$ in $(\mathbf{a}, \mathbf{b})$ and is $10 \mathrm{~m}$ in $(\mathbf{c})$ (a) CTL run

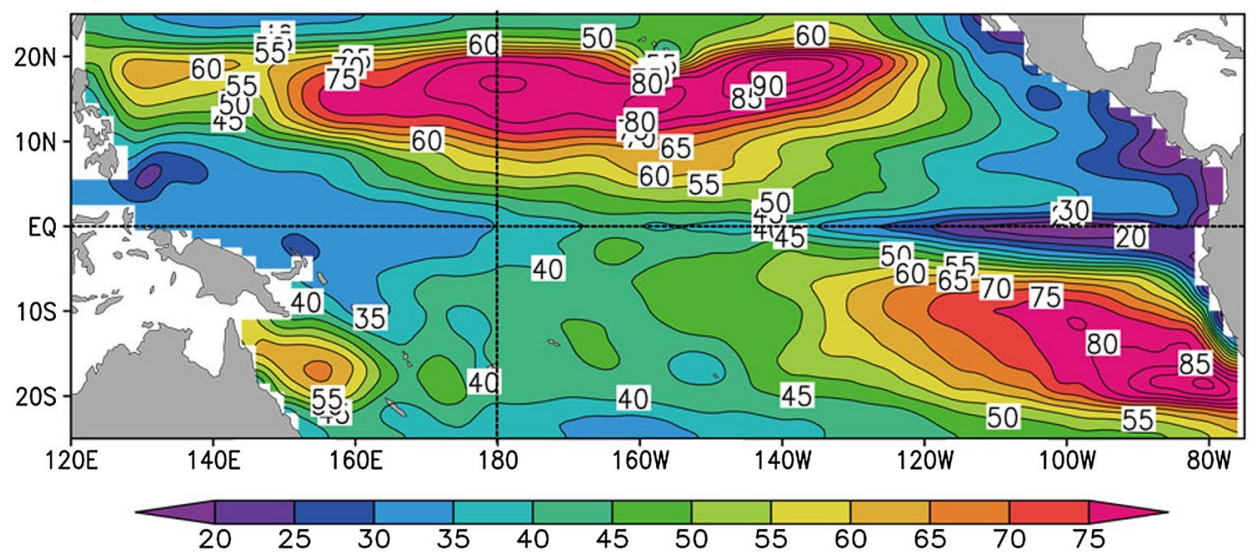

(b) SV run

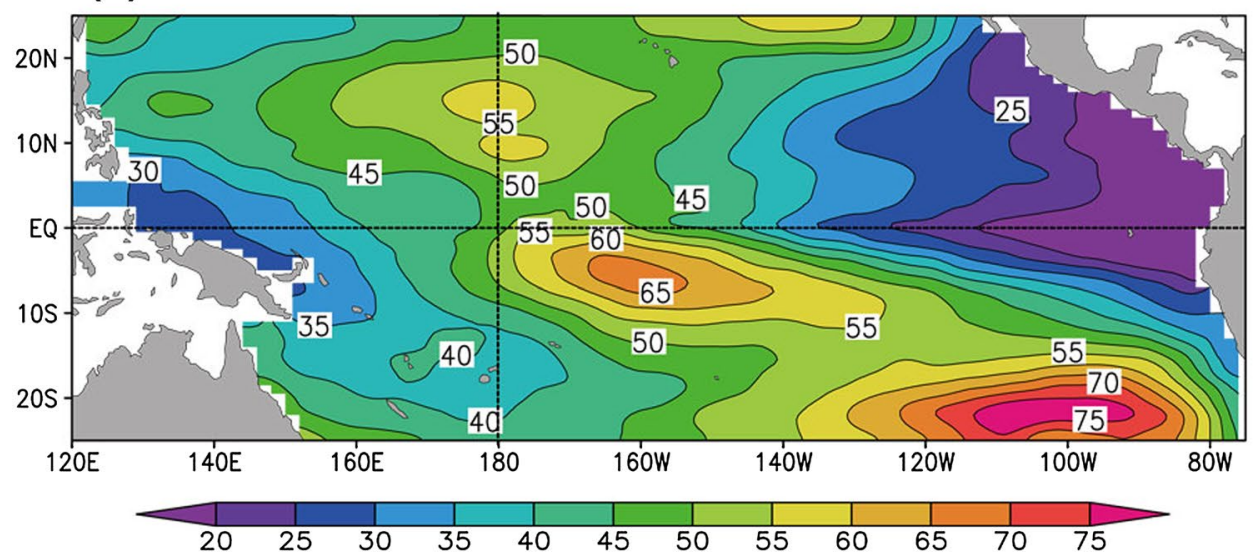

(c) MLD differences (SV-CTL)

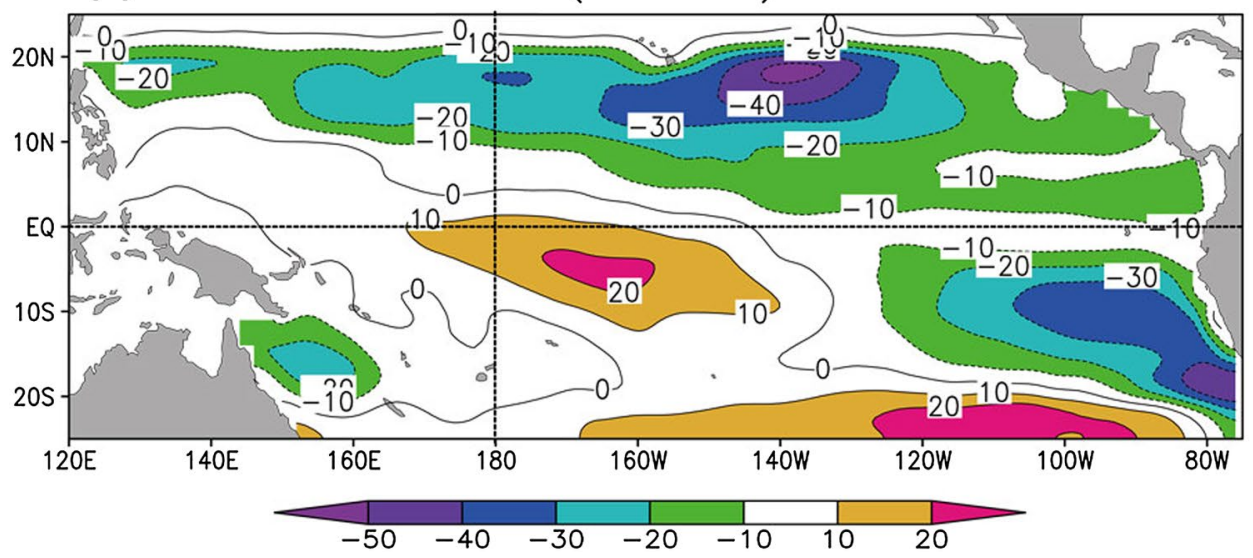


than $20 \mathrm{~m}$ arises in the northern basin and off the coast of Peru. In the central basin, the deep ML is reproduced, which is comparable to the observations. Because the $m_{0}$ represents the rate of TKE transfer from wind towards mixing, it has a great influence on the MLD. For example, the large $m_{0}$ means more energy is extracted from wind to TKE. As a consequence, the turbulent motion is vigorous and the $\mathrm{ML}$ is deep. Since the $m_{0}$ is optimally derived with constraint imposed by the observations in this study, it represents the mixing intensity in the upper ocean more realistically and gives rise to the more realistic MLD simulations.

Simulations of the MLD annual cycle along the equator are shown in Fig. 6. Both runs capture the essential features, including the ML shoaling in spring and the subsequent deepening in April-July over the eastern equatorial Pacific. The CTL run, however, exhibits some obvious discrepancies compared with the observations. For example, the phasing of the simulated seasonal cycle does not match well with the observations and the observed westward propagation is missing during spring. The simulated seasonal cycle is overestimated in the eastern equatorial Pacific, but is underestimated in the central equatorial Pacific. The maximum amplitude tends to occur around $120-140^{\circ} \mathrm{W}$, which is farther east than the observed. Clearly, the seasonal cycle is more adequately represented in the SV run. The westward propagation of the ML shoaling during spring is well captured; the maximum amplitude shifts westward to the right place; the unrealistical deepening of the ML during April-July is reduced somehow to match the corresponding observations.

Model performance for interannual variability of MLD is also improved using the optimized $m_{0}$. As has been extensively studied, the El Niño-Southern Oscillation (ENSO) is the dominated interannual signal originating from the airsea interaction in the tropical Pacific (e.g., Bjerknes 1969; Zebiak and Cane 1987), and the interannual variability of the MLD appears as a response to El Niño with a shallow ML in the western-central Pacific and a deep ML in the eastern equatorial Pacific. Figure 7 displays an example for the MLD anomalies in the mature phase of 2015/2016 El Niño event. The El Niño is characterized by a positive freshwater flux into ocean and a decrease in wind stress over the central equatorial Pacific, both of which contribute to the ML shoaling. The results from the CTL run reveal that the original KTN model does not well capture the responses of MLD to the interannual variability of atmospheric forcing appropriately. Compared with the observations in the central basin (Fig. 7a), the negative MLD anomaly in the CTL run (Fig. 7b) is much weaker than observation with the maximum discrepancies exceeding $20 \mathrm{~m}$. Although the differences are still nontrivial, the $\mathrm{SV}$ run produces a more realistic simulation under the El Niño conditions with a reduction in MLD biases by $\sim 10 \mathrm{~m}$ over the central equatorial Pacific (Fig. 7c).
Dynamical roles of the changes in MLD in the ocean have been a major concern in climate studies. For example, Huang et al. (2007) used the varying $m_{0}$ from 0.4 to 12.5 to study its roles in regulating the meridional mass and heat fluxes. Hazeleger and Haarsma (2005) selected two different values of $m_{0}$ to discuss its influences on the tropical Atlantic climate. Although the $m_{0}$ is arbitrarily selected, their studies reveal its significant effects on ocean circulation modeling. Therefore, the impacts of the optimal $m_{0}$ on the upper ocean currents and SST will be discussed in the following sections.

\subsection{The effects on the circulation}

Figure 8 displays the vertical distributions of the equatorial currents from the observations, the CTL run and the SV run. The general circulation of the upper tropical Pacific Ocean is characterized by the strong zonal currents and the subtropical cells (STCs). We employ the mean ADCP sections of Johnson et al. (2002) for representing the observed zonal currents at the equator. Both runs realistically capture the patterns of the equatorial currents system, including the north equatorial countercurrent (NECC), the equatorial undercurrent (EUC) and the south equatorial current (SEC). The simulated EUC, although it extends slightly deeper, displays the strength and the core location comparable to the observed; the NECC and the SEC are less intense with a weakening of $10-20 \mathrm{~cm} \mathrm{~s}^{-1}$. Differences in the NECC and the EUC between the CTL run and the SV run seem subtle; some improvements occur in the SEC. For example, the SV run tends to reduce the too much westward flow of the SEC near the surface at $110^{\circ} \mathrm{W}$ (Fig. 8e).

Figure $9 \mathrm{a}$ shows the observed zonal currents at $140^{\circ} \mathrm{W}$ on the equator from the TAO moorings (available online at http://www.pmel.noaa.gov/tao/). One notable feature of the seasonal variation in the SEC is the so-called spring reversal: during August-March, the SEC flows westward; it reverses direction during April-July. The related seasonal variation in the EUC is also evident. During November-February, the EUC is weakest; it is strongest in May with its strength peaking above $120 \mathrm{~cm} \mathrm{~s}^{-1}$, accompanied by its surfacing and the reversed SEC. Basic features of the seasonal variation are captured well, but there are some discrepancies, including the strength of the spring reversal and the vertical extent of the EUC (Fig. 9b, c). In general, the modeled zonal currents seem not very sensitive to the improvements in the MLD simulations, but this is not the case for the meridional currents.

The STC consists of the water subduction in the subtropics, flowing equatorward and westward in the pycnocline, feeding the EUC in the equatorial regions, resurfacing in the eastern equatorial Pacific and returning back to the subtropics (Rothstein et al. 1998; Liu and Philander 2001). As demonstrated before, the STC 
(a) Observation

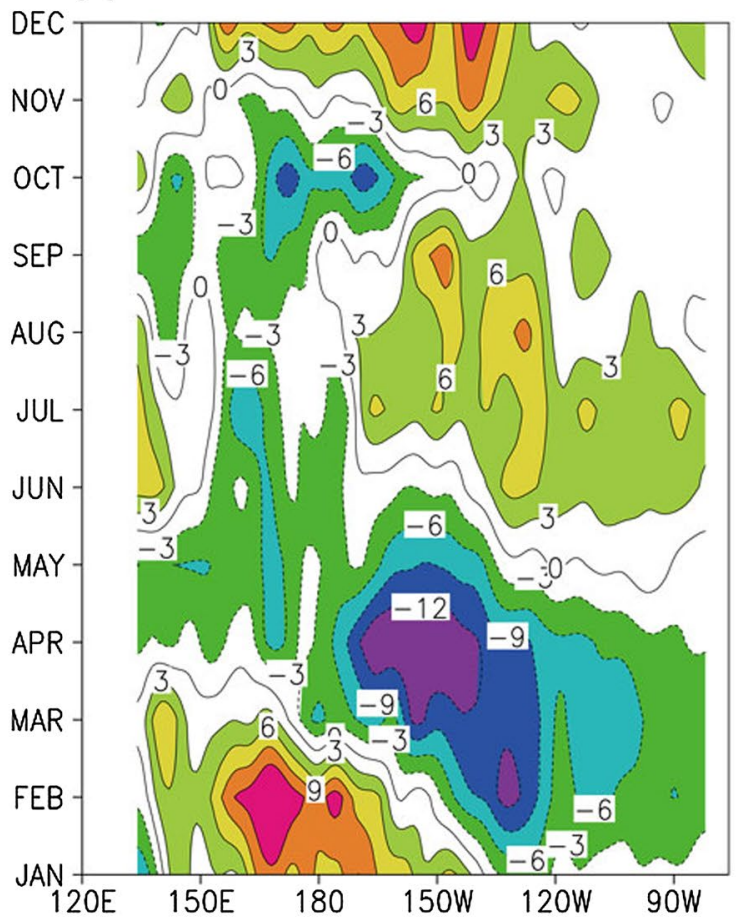

(c) SV run

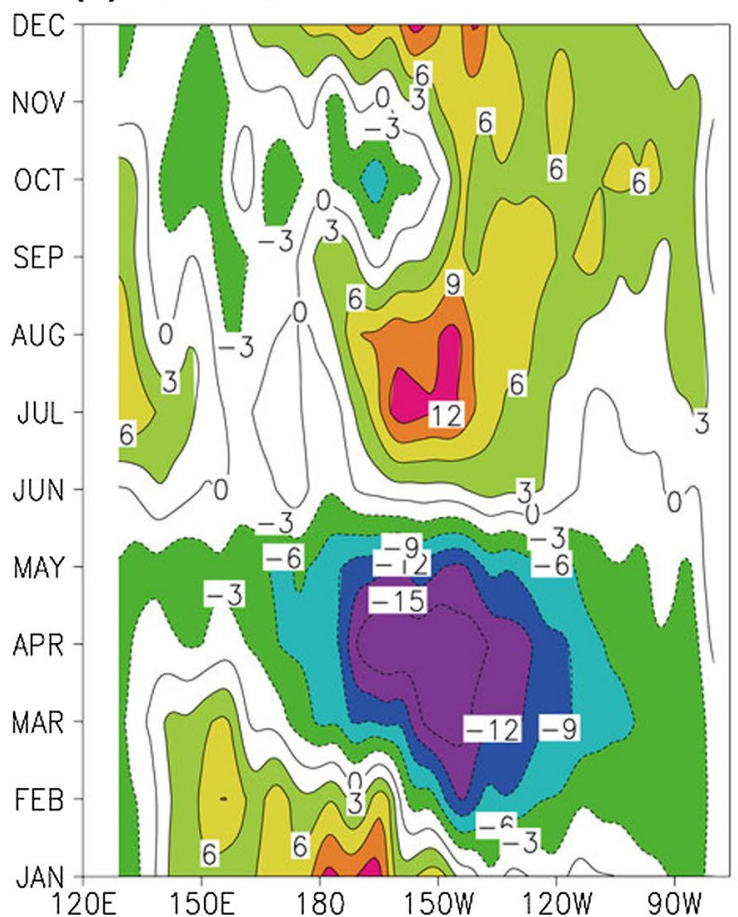

(b) CTL run

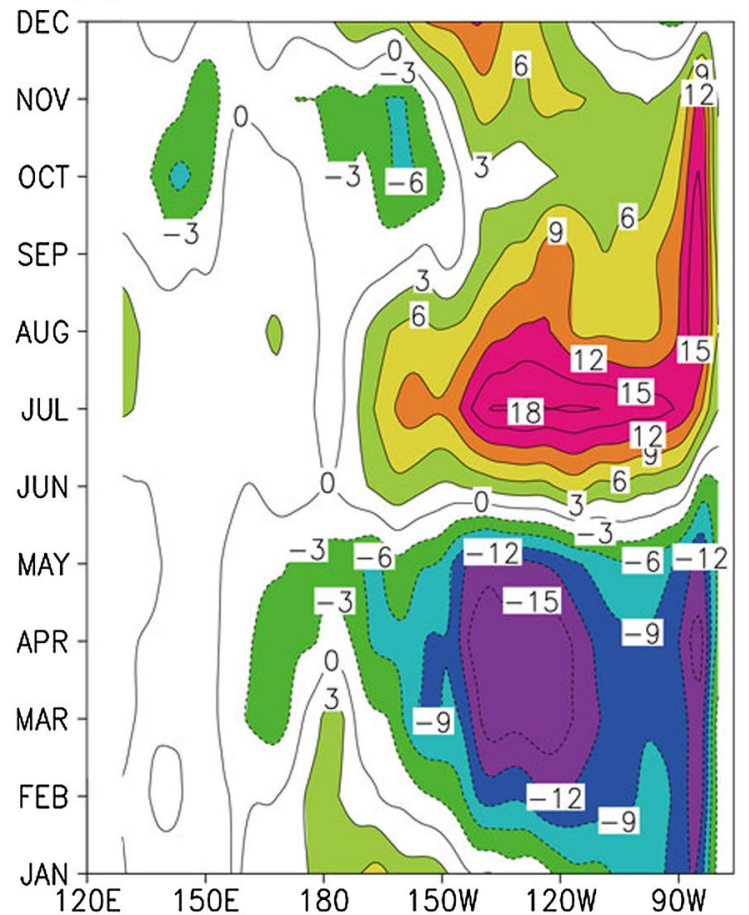

(d) Diff in seasonal cycle

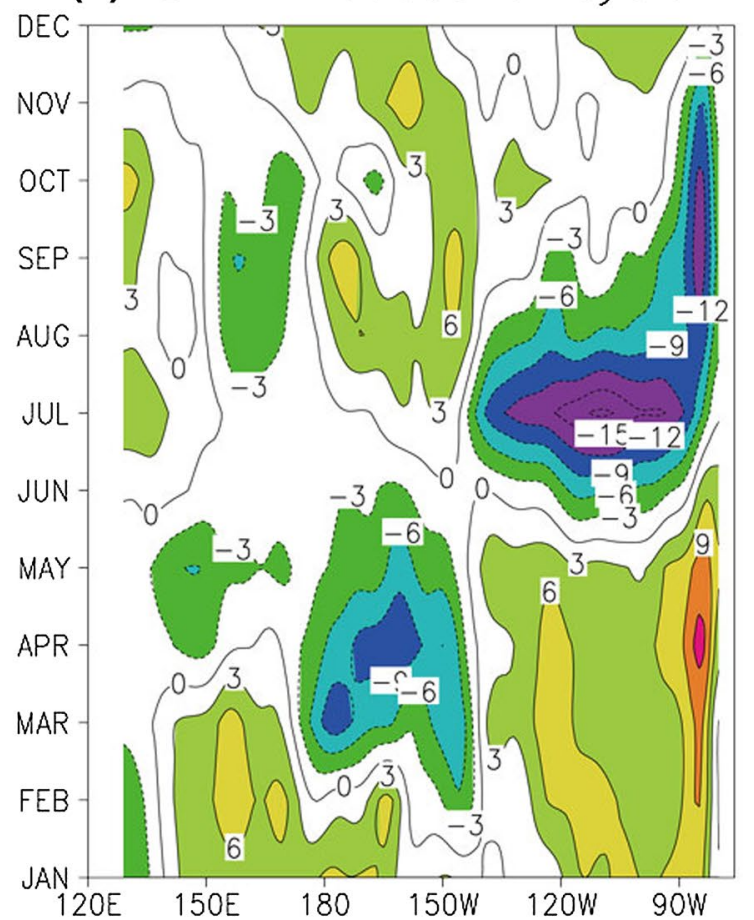

Fig. 6 The MLD seasonal cycle along the equator for (a) the observation, (b) the CTL run, (c) the SV run, and (d) their differences (the SV run minus the CTL run). The contour interval is $3 \mathrm{~m}$

plays an important role in the climate system by controlling the exchanges of heat and mass between the equator and the subtropics (Zhang et al. 1998). Due to the lack of the direct current measurements, we employ the outputs from the GODAS for comparisons. Figure 10 displays the 
Fig. 7 Horizontal patterns of interannual MLD anomalies in December 2015 from (a) the observation, (b) the CTL run and (c) the SV run. The contour interval is $5 \mathrm{~m}$ (a) Observation

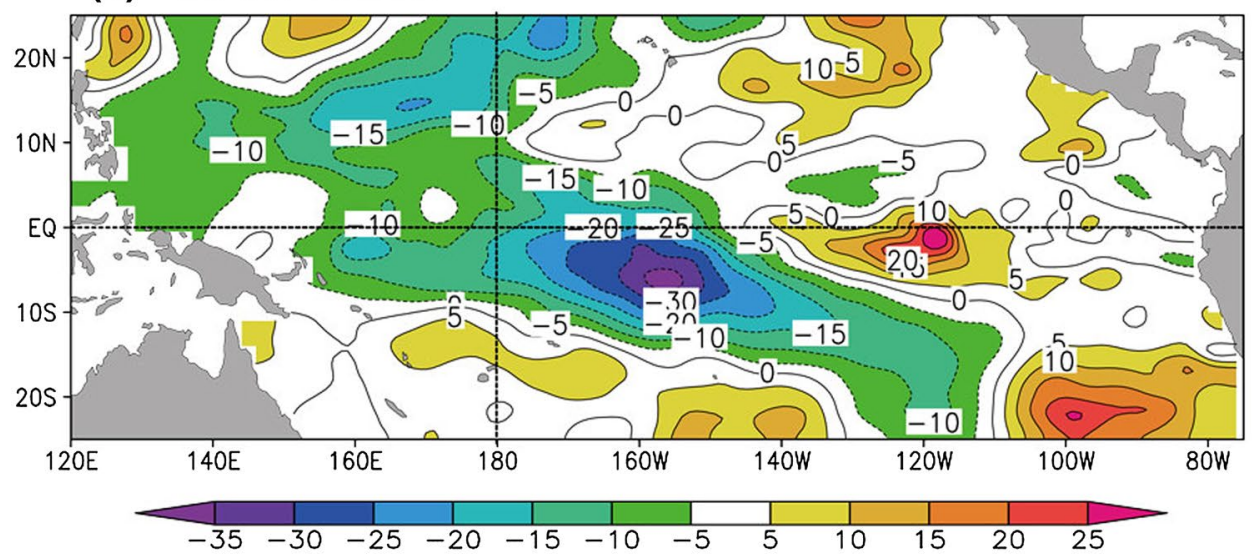

(b) CTL run

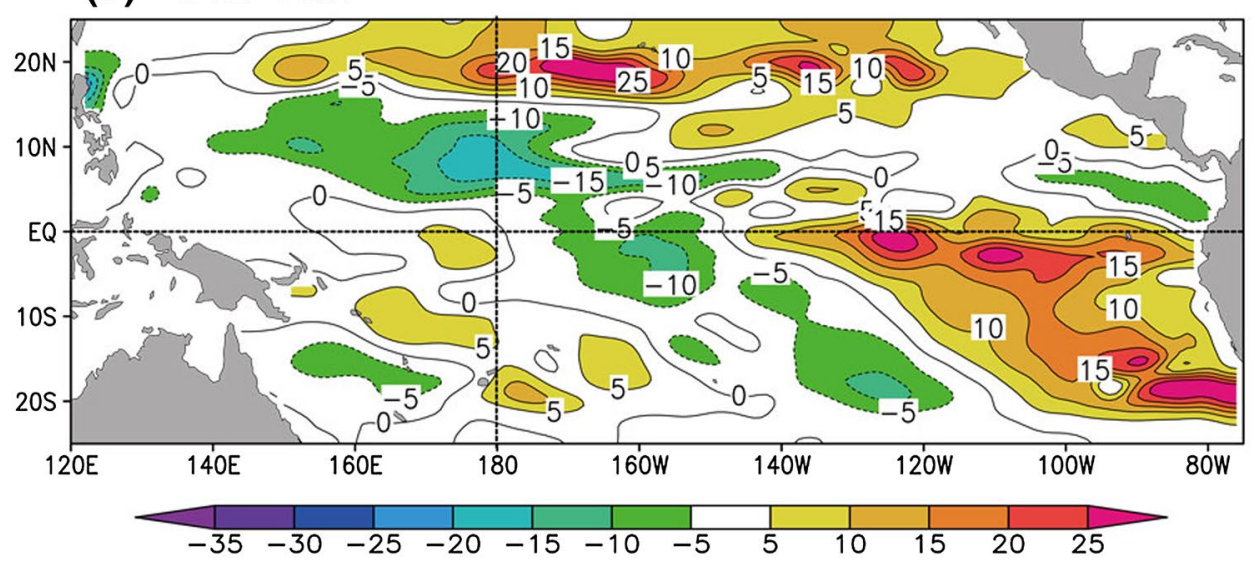

(c) SV run

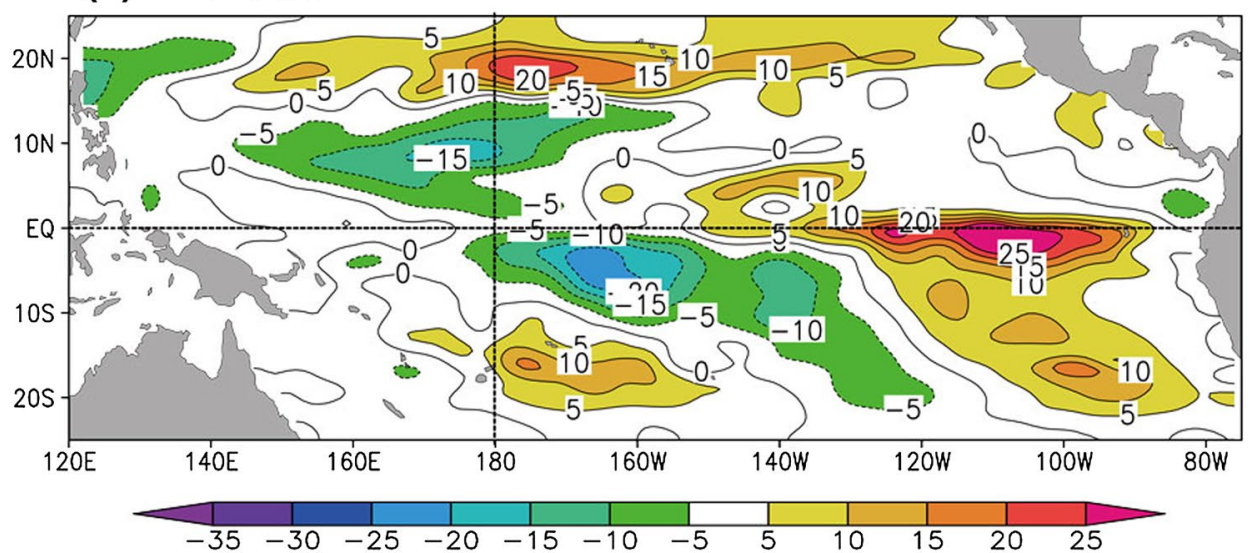

annual-mean meridional currents for the section along $140^{\circ} \mathrm{W}$. It is evident that the SV run (Fig. 10c) bears a strong resemblance with the GODAS (Fig. 10a). Compared with that in the CTL run (Fig. 10b), the meridional transport of water to the high latitudes is increased within the ML accompanied with more equatorward transport in the subsurface layer, resulting in a spin-up of the STC and a strengthening of the upwelling.

\subsection{The effects on the SST}

The variation of MLD affects SST not only by changing the depth over which the surface heat flux is distributed, but also by the entrainment of subsurface waters at the bottom of ML. Since the MLD is well simulated, we discuss its influences on the modeled SST. The OGCM performance has been examined extensively in the tropical Pacific (Chen et al. 1994b; Murtugudde et al. 1996; Zhang et al. 2006), and 
(a) Observation (Equator)

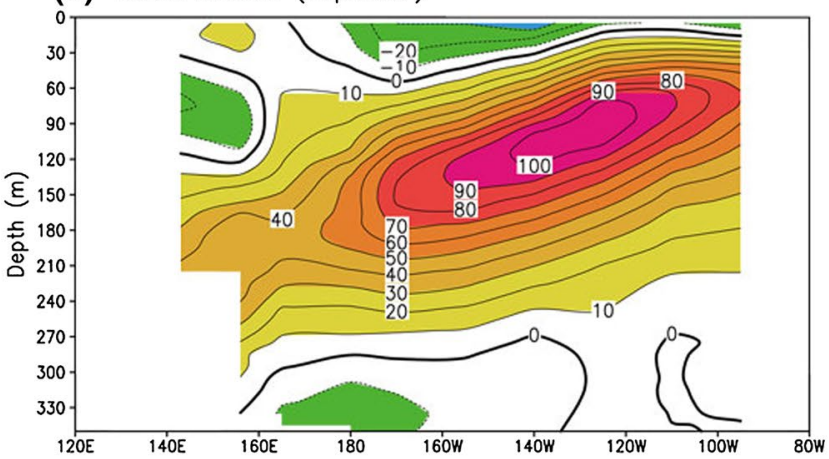

(c) CTL run (Equator)

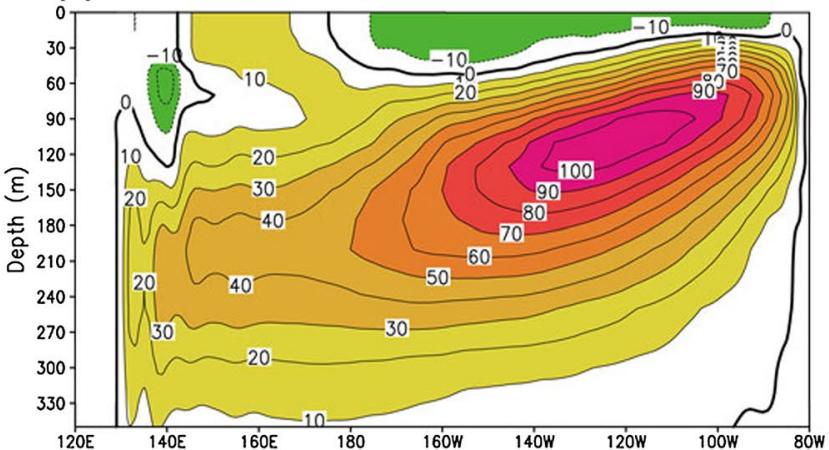

(e) SV run (Equator)

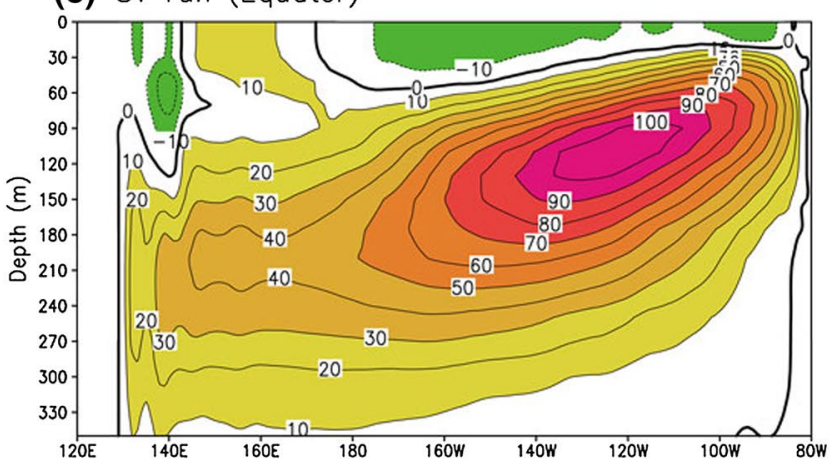

(b) Observation (140W)

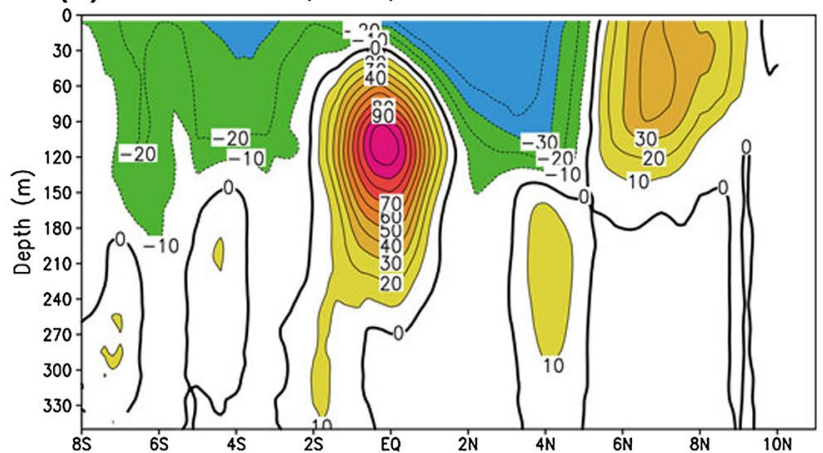

(d) CTL run (140W)

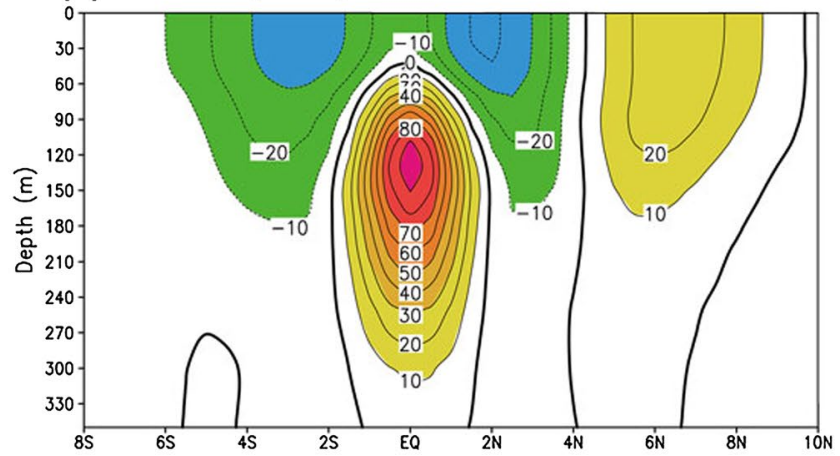

(f) SV run (140W)

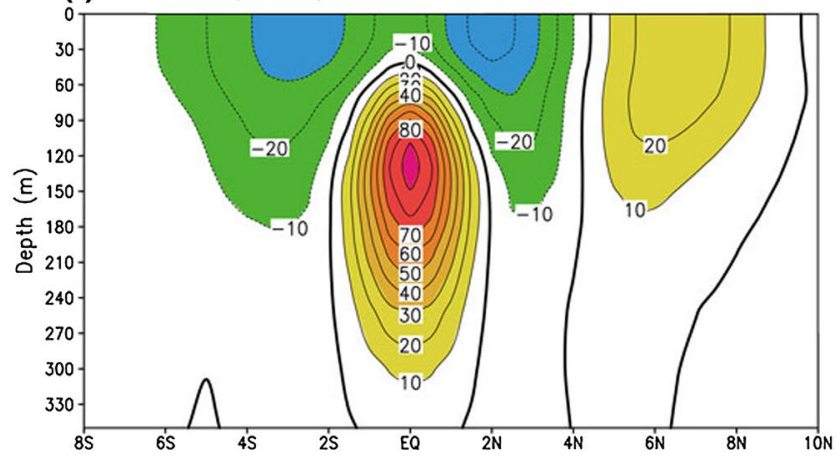

Fig. 8 Annual-mean zonal currents for the (left panels) zonal-verical sections along the equator and (rigth panels) meridional-vertical secions along $140^{\circ} \mathrm{W}$ from $(\mathbf{a}, \mathbf{b})$ the observation, $(\mathbf{c}, \mathbf{d})$ the CTL run and $(\mathbf{e}, \mathbf{f})$ the $\mathrm{SV}$ run. The contour interval is $10 \mathrm{~cm} \mathrm{~s}^{-1}$

we only show some relevant results. Relative to the CTL run, a systematic cooling effect in the SV run is evident over the eastern equatorial Pacific: negative SST differences between the two runs can be as large as $0.4{ }^{\circ} \mathrm{C}$ (Fig. 11). To understand the mechanisms by which the improvement in MLD simulations acts to cool the SST, a heat budget is performed for the ML on the equator.

Figure 12 shows the differences in the heat budget terms between the two runs. The surface heat flux (Fig. 12a) and the vertical mixing (Fig. 12b) are the two terms that are pronouncedly modulated by the seasonally and spatially varying $m_{0}$. The surface heating is represented by $Q_{s f} /\left(c_{p} \rho h\right)$ where $Q_{s f}$ is the heat flux absorbed in the ML, $c_{p}$ and $\rho$ are the specific heat and density of the seawater, and $h$ is the
MLD. In January-May, the modeled MLD is deeper around $100-120^{\circ} \mathrm{W}$ in the SV run (Fig. 6d) and the value of $h$ is larger, resulting in a reduced warming effect from the surface heating. As a result, the negative differences in SST emerge in the SV run relative to the CTL run. In June-September, the MLD in the SV run is shallower and the net heating effect is enhanced. It is also the case for the cooling effect from the vertical mixing $Q_{m i} /\left(c_{p} \rho h\right)$, where $Q_{m i}$ is the turbulent heat flux at the base of the ML. Differences in annually averaged SST budget terms along the equator are displayed in Fig. 13a. Note that the varying $m_{0}$ has different effects on the eastern and western sides of $120^{\circ} \mathrm{W}$, which is due to its opposite effects on the MLD seasonal cycle (Fig. 6d). For example, in the eastern regions, the amplitude of MLD 
(a) Observation

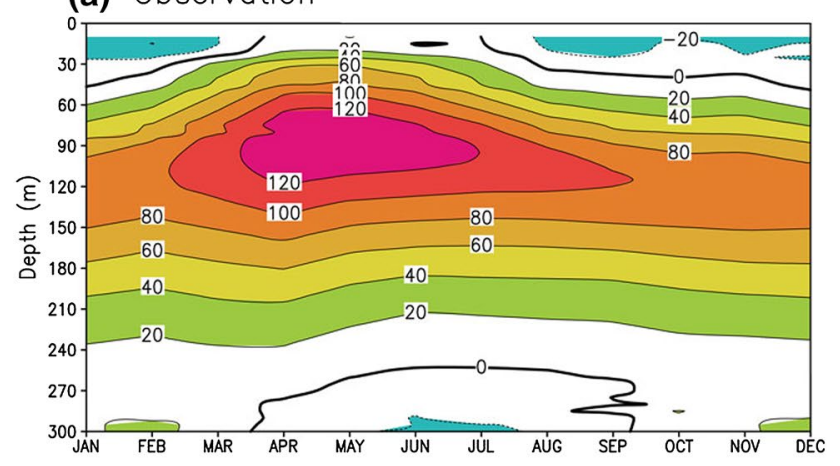

(b) CTL run

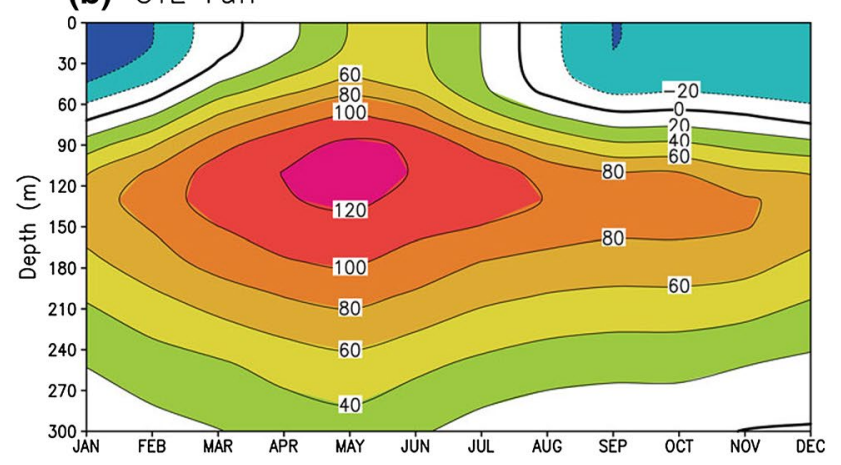

(c) SV run

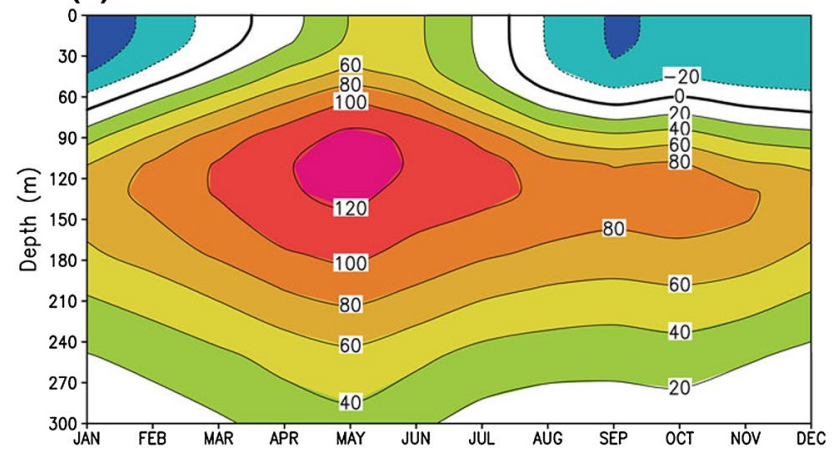

Fig. 9 Seasonal variations in the zonal currents at $140^{\circ} \mathrm{W}$ on the equator for (a) the observation from TAO, (b) the CTL run and (c) the SV run. The contour interval is $20 \mathrm{~cm} \mathrm{~s}^{-1}$

seasonal cycle is reduced in the SV run; the seasonal variation of $h$ over a year is relatively weak. So the accumulating effects of $Q_{s f} /\left(c_{p} \rho h\right)$ and $Q_{m i} /\left(c_{p} \rho h\right)$ throughout 1 year are lower in the SV run than those in the CTL run, leading to the warming effect from the surface heat flux and the cooling effect from the vertical mixing that are both reduced. In the western regions, the amplitude of MLD seasonal cycle is enhanced, resulting in the corresponding modulations that are opposite to those in the eastern regions. In general, the differences in the heat budget terms from the surface heating and vertical mixing are directly subject to the changes in the MLD and their effects on annual-mean SST are compensated for by each other, leading to the subtle annual-mean SST differences. It is the case for the western sides of $120^{\circ} \mathrm{W}$ on the equator and the cooling regions adjacent to the equator (Fig. 13b). But in the eastern sides of $120^{\circ} \mathrm{W}$, the cooling effect from the vertical advection is largely enhanced (green line in Fig. 13a), resulting in a reduced cooling effect from the vertical mixing further (blue line in Fig. 13a). It is consistent with the result from Schopf and Cane (1983), indicating that the variation of MLD induced by vertical mixing can be considerably influenced by the upwelling at the ML base. Thus, the reduced cooling effect from the vertical mixing should be considered as a response to the enhanced vertical advection. As the enhanced vertical advection is the main process responsible for the modulation of the SST heat budget, the resultant SST differences between the SV run and the CTL run are negative over the eastern equatorial Pacific, leading to a large scale cooling pattern.

\section{Discussion: the MLD and its relationship with the combined effects of the spatially and seasonally varying $m_{0}$ and wind}

OGCM simulations from the CTL run indicate that the original KTN model is not capable of realistically depicting the MLD and its evolution in the tropical Pacific Ocean, with the overestimated in the northern basin and the underestimated in the central basin. The biases can be substantially reduced by introducing the spatially and seasonally varying fields of $m_{0}$. To some extent, a compensating relationship emerges among the values of $m_{0}$, the MLD and the wind stirring effects so that realistic MLD simulations can be achieved. For example, in the regions where wind is weak, a larger $m_{0}$ value is required to simulate the MLD as in reality. In addition, the varying $m_{0}$ representation is closely related to the scaling of the surface wind effect and the MLD under the stabilizing buoyancy flux. To justify the inverse method we proposed in this study, in this section, we discuss the similarity of our method to others previously analyzed.

Under the stabilizing buoyancy flux, the ML tends to retreat to a shallower depth within which the TKE input by wind stress is sufficient enough to well mix. Hence, the term on the left-hand side and the second term on the right-hand side of Eq. (1) are equal to zero, resulting in

$h=-\frac{2 m_{0} u_{*}^{3}}{B}$

which is the Monin-Obukhov length $\left(L_{\mathrm{mo}}\right)$ for $m_{0}=1.25$. It is generally recognized that non-negligible biases exist in this length for scaling MLD because of the lack of Earth's rotation effect (Garwood et al. 1985a; Yoshikawa 2015). Depth of the turbulent Ekman boundary layer (Ekman 1905) is given by 
(a) GODAS

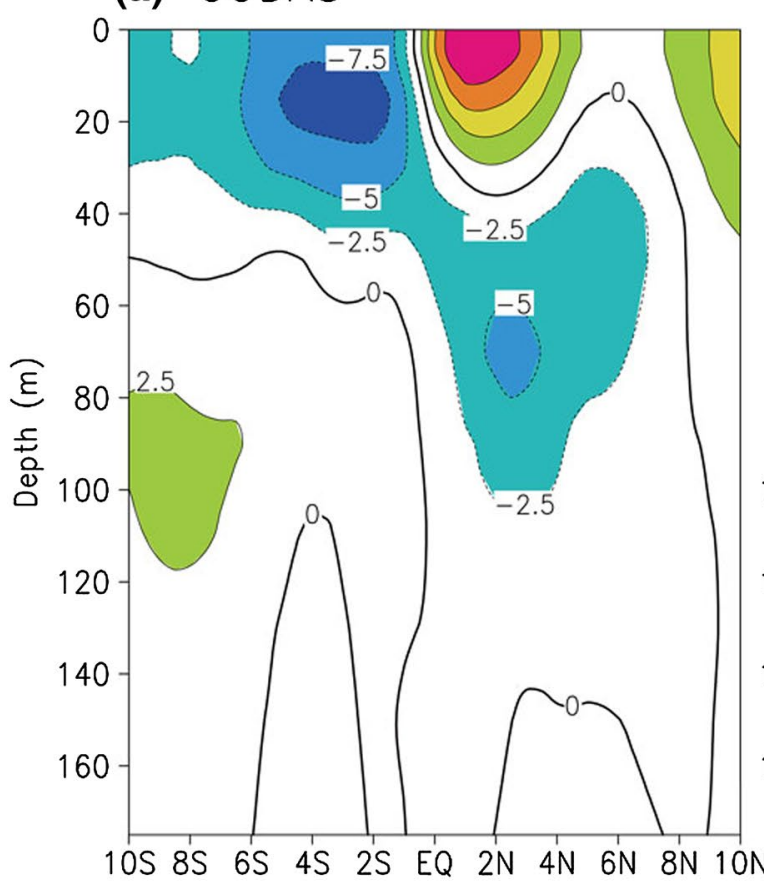

(c) SV run

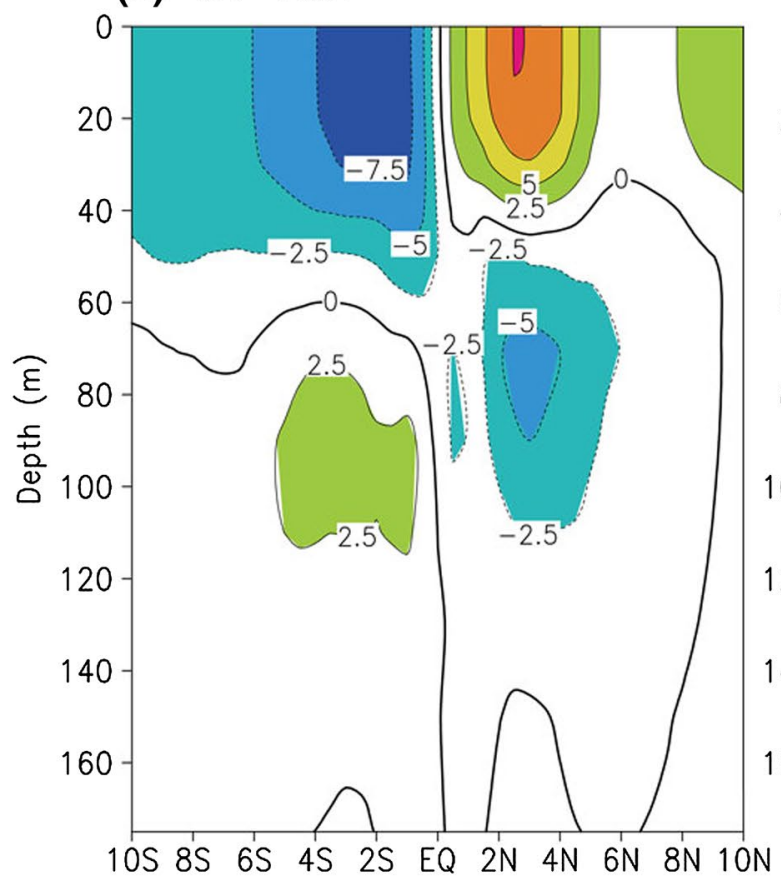

(b) CTL run

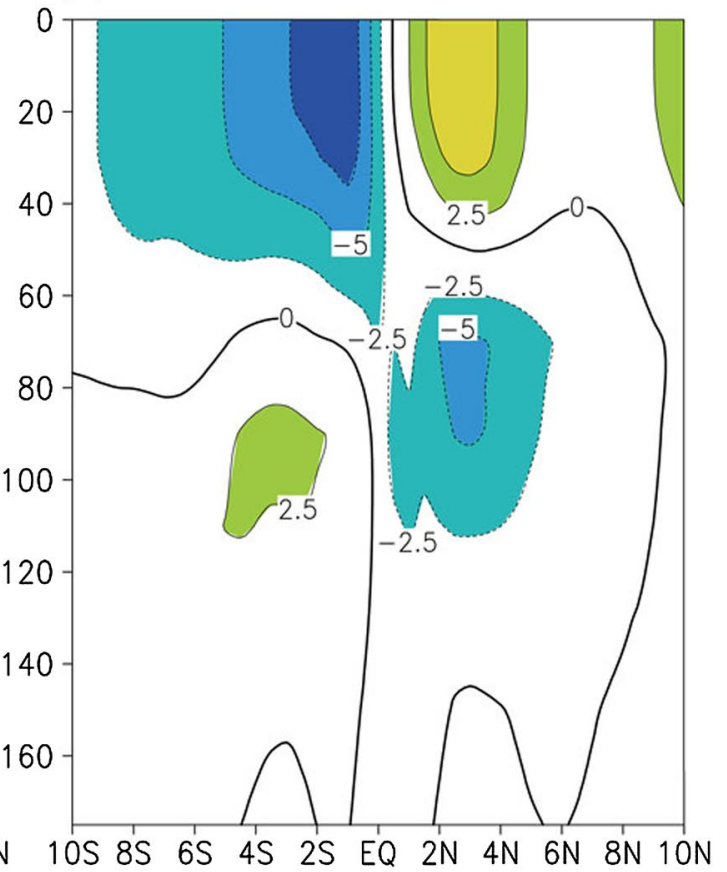

(d) Differences (SV-CTL)

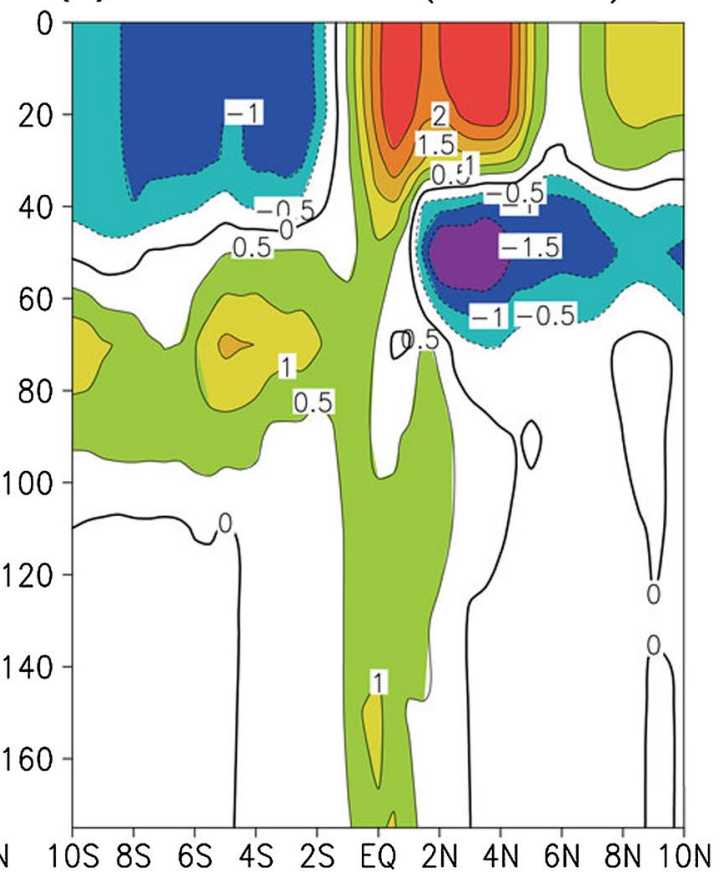

Fig. 10 Annual-mean meridional velocity along $120^{\circ} \mathrm{W}$ from (a) the GODAS, (b) the CTL run, (c) the SV run, and (d) their differences (the SV run minus the CTL run). The contour interval is $2.5 \mathrm{~cm} \mathrm{~s}^{-1}$ in $(\mathbf{a}-\mathbf{c})$ and $0.5 \mathrm{~cm} \mathrm{~s}^{-1}$ in (d)

$$
L_{e k}=\left(\frac{K_{m}}{|f|}\right)^{\frac{1}{2}},
$$

which scales the wind-induced mixing layer in the presence of Earth's rotation. In order to fit the logarithmic current profile within the boundary layer, the eddy viscosity coefficient $K_{m}=\kappa u_{*} L_{e k}$ and the turbulent Ekman boundary layer is modified as 
Fig. 11 Annual-mean SST differences between the SV run and the CTL run. The contour interval is $0.1^{\circ} \mathrm{C}$

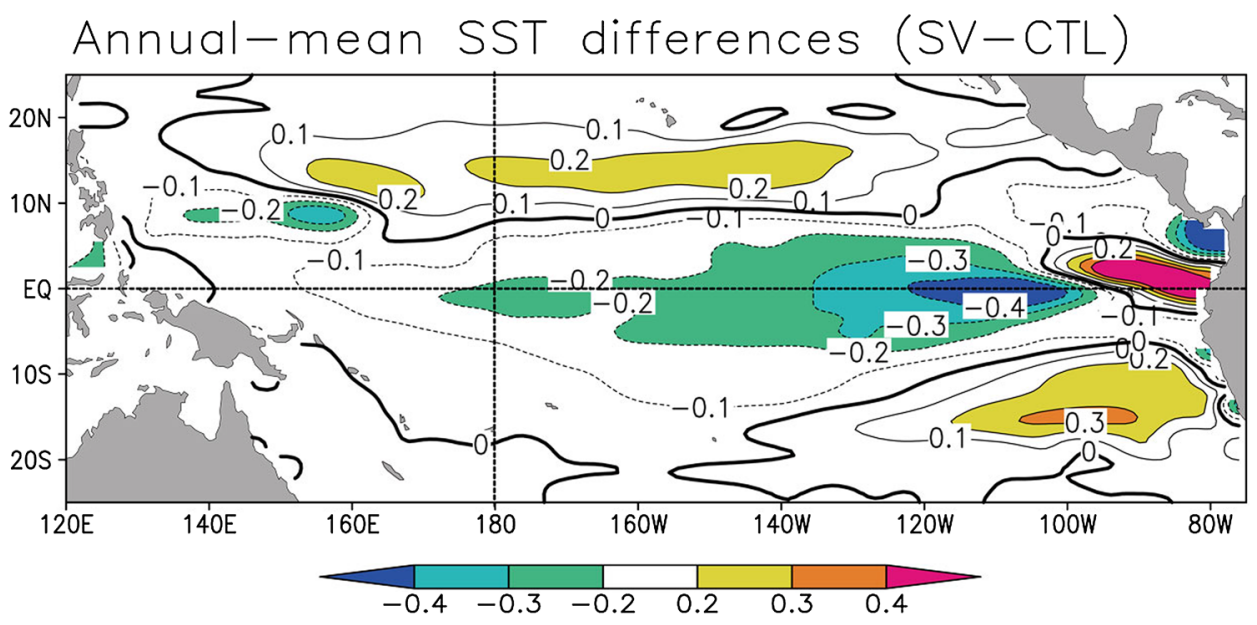

$L_{e k}=\kappa \frac{u_{*}}{f}$

(Rossby and Montgomery 1935). The variation of MLD is found to be proportional to $L_{\mathrm{ek}}$ in the low latitude Pacific Ocean (Lee et al. 2015). Nevertheless, $f$ vanishes when approaching to the equator and the $L_{\mathrm{ek}}$ is too deep to limit the downward propagation of TKE.

For discussing the effects of wind stress on the shoaling of MLD, correlation between Argo MLD and $u_{*}$ during the period 2005-2015 is shown in Fig. 14a. Correlations exceed 0.6 in most of the regions equatorward of $20^{\circ}$ latitude, which implies that the MLD is directly related with the local variability of wind stress there. Therefore, a scatterplot of their relationship during the shoaling period with correlations exceeding 0.6 is shown in Fig. 14b. It reveals that the scatterplot has a relatively flat top edge and a curve lower edge, which indicates that two types of MLD responses to $u_{*}$ exist in the tropical Pacific: the linear and the cubic relationships, respectively.

It is plausible that these observations-derived linear and cubic relationships correspond to $L_{\mathrm{ek}}$ and $L_{\mathrm{mo}}$ as given above. $L_{\mathrm{ek}}$ increases dramatically to a very large value when approaching to the equator, but the evolution of the Argo MLD is relatively moderate in the tropical Pacific. Although $M L D \approx 0.44 L_{e k}$ is valid for some regions (Lozovatsky et al. $2005)$, it is questionable to scale the MLD solely by $L_{\mathrm{ek}}$ in the tropical Pacific. On the other hand, vertical penetration of the wind-generated turbulence can be scaled by $L_{g 85}=u_{*} / \tilde{f}$ (Garwood et al. 1985b; Gerkema et al. 2008), where $\tilde{f}$ is the tangential component of the planetary vorticity and is traditionally negligible under the ' $f$-plane' approximation. Although some theoretical analysis and numerical model results contradict the idea and demonstrate a trivial influence of $\tilde{f}$ on the MLD (Fernando 1987; Galperin et al. 1989), $L_{\mathrm{g} 85}$ matches the evolution of the Argo MLD well in our analysis (red lines in Fig. 14c). When referring to the cubic relationship, it reveals a significant discrepancy between the Argo MLD and $L_{\text {mo }}$ (blue scatters in Fig. 14c), indicating that the $m_{0}$ needs to be justified when scaling the observed MLD. The depth scales associated with $L_{\mathrm{mo}}$ and $L_{\mathrm{ek}}$ are proposed by assuming the TKE dissipation rate to be proportional to $f u_{*}^{2} h$ rather than $u_{*}^{3}$ (Garwood 1977). Under the stabilizing buoyancy flux, the equilibrium MLD is given as

$L_{g 77}=\frac{1}{a_{g 77} / L_{e k}+b_{g 77} / L_{m o}}$.

We assume the $L_{\mathrm{g} 77}$ to be proportional to the observational MLD and introduce $L_{\mathrm{g} 77}$ into the KTN model, resulting in

$m_{0}=\frac{1}{2 \kappa b_{g 77}}\left(1-a_{g 77} \frac{f h}{\kappa u_{*}}\right)$,

which is similar with the formula proposed by Resnyanskiy (1975), in which $a_{\mathrm{g} 77}=0.325$ and $b_{\mathrm{g} 77}=1.563$. The atmospheric stabilized MLD is given by

$L_{z 72}=\left(L_{e k} L_{m o}\right)^{1 / 2}$,

(Zilitinkevich 1972). It is extended as

$L_{z 02}=\frac{1}{\left(a_{z 02} / L_{e k}^{2}+b_{z 02} / L_{z 72}^{2}\right)^{1 / 2}}$,

(Zilitinkevich and Esau 2002), so that

$m_{0}=\frac{1}{2 \kappa b_{z 02}}\left(\frac{\kappa u_{*}}{f h}-a_{z 02} \frac{f h}{\kappa u_{*}}\right)$,

where $a_{\mathrm{z} 02}=0.28$ and $b_{\mathrm{z} 02}=0.31$ suggested by Yoshikawa (2015) for the oceanic MLD. Note that $h$ is dependent on $u_{*}$ and their relationship lies between the linear relation and the cubic relation $\left(h \sim u_{*}^{a}, 1<a<3\right)$, as revealed in 
Fig. 12 Differences (the SV run minus the CTL run) in seasonal cycle of the SST budget terms for (a) the surface heat flux, (b) the vertical mixing, (c) the horizontal advection, (d) the vertical advection and (e) the SST tendency. The contour interval is $0.4{ }^{\circ} \mathrm{C}$ month ${ }^{-1}$ (a) Surface heat flux

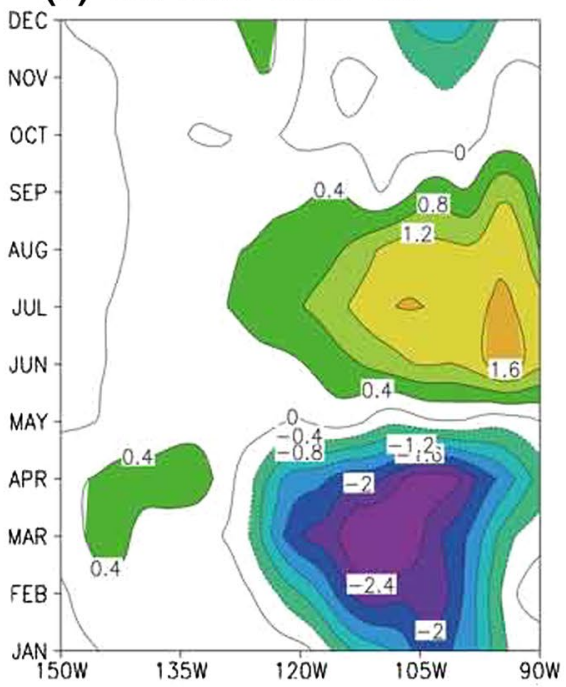

(c) Horizontal advection

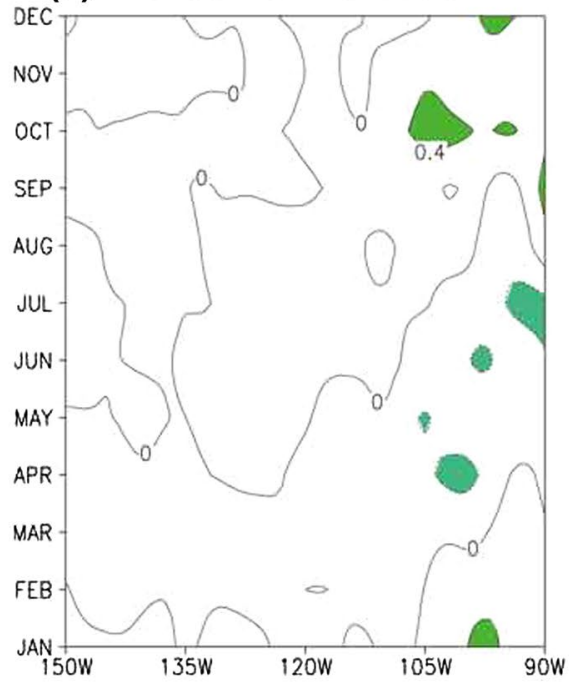

(e) SST tendency

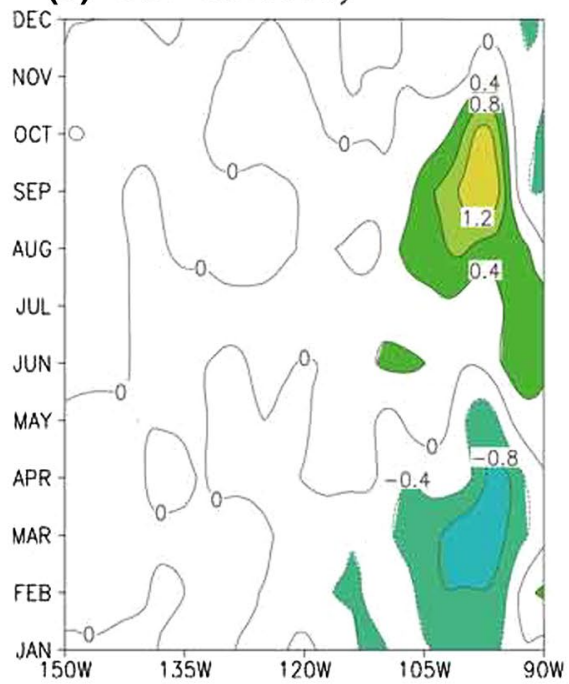

(b) Vertical mixing

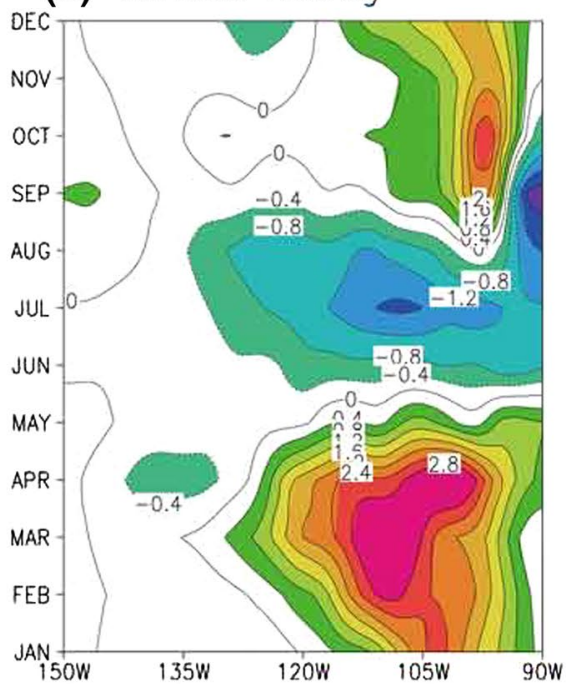

(d) Vertical advection

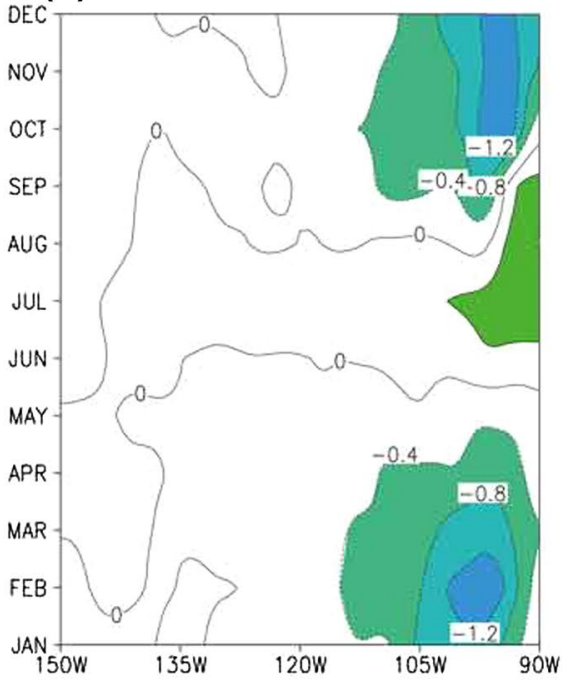


Fig. 13 Differences (the SV run minus the CTL run) in the annually averaged SST budget terms (a) along the equator and (b) along $2^{\circ} \mathrm{N}$. The unit is ${ }^{\circ} \mathrm{C}$ month $^{-1}$ (a) Diff in SST budget terms along the equator

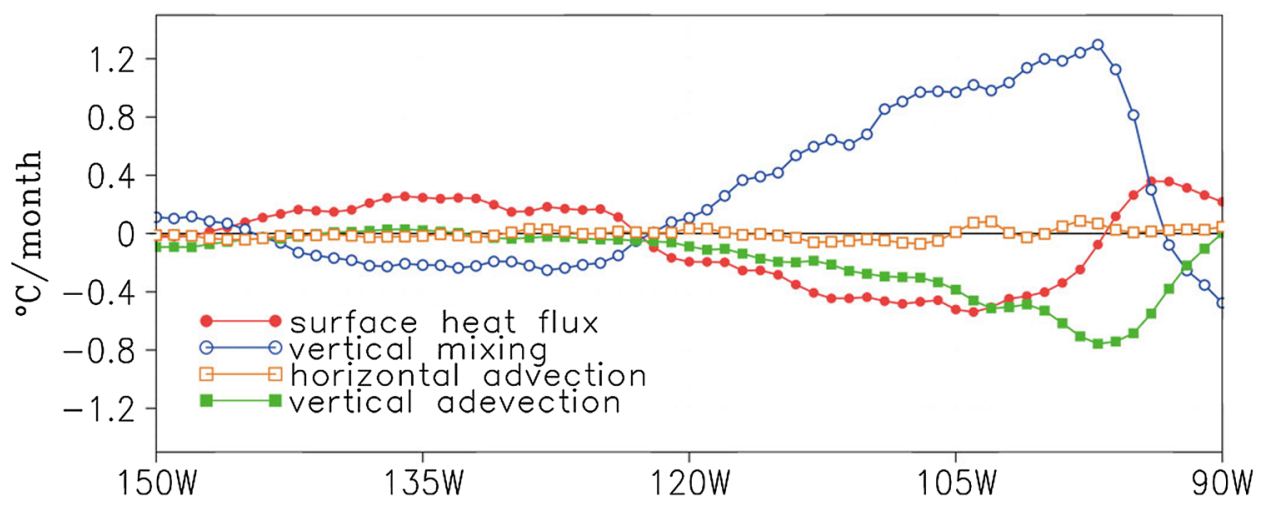

(b) Diff in SST budget terms along $2^{\circ} \mathrm{N}$

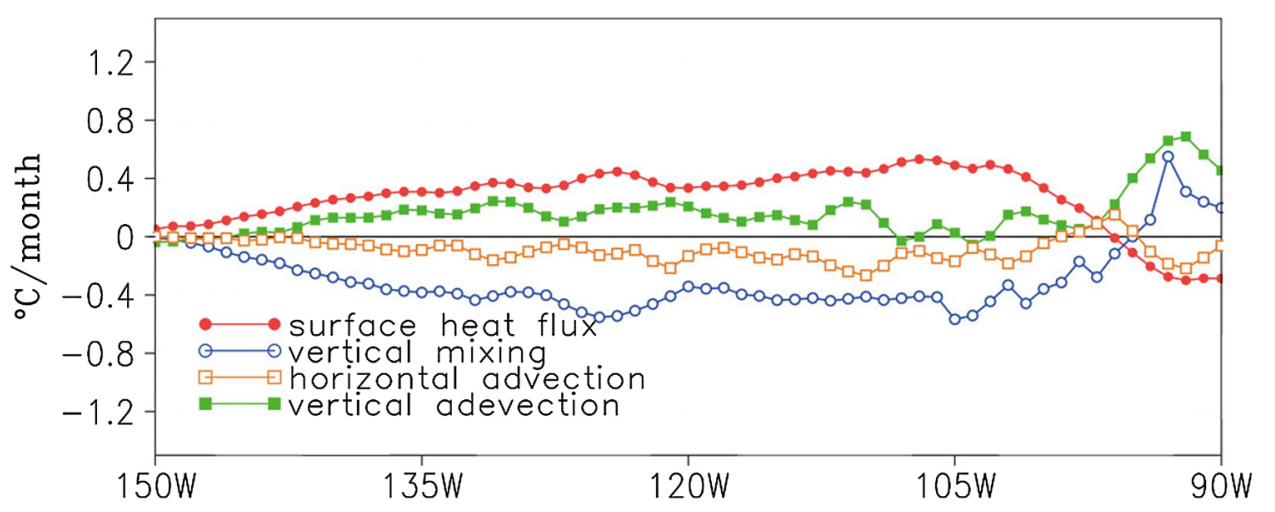

Fig. 14b. Thus, the Eq. (7) and Eq. (10) show that the large $m_{0}$ corresponds to the weak wind, which is consistent with our findings in the optimized calculation. In the previous study, the Argo MLD is averaged over its shoaling period and its global distribution resembles to that of $L_{\mathrm{g} 77}, L_{\mathrm{z} 72}$ or $L_{\mathrm{z} 02}$ (Yoshikawa 2015). But the evolution of the Argo MLD during the shoaling period is rather different from the three length scales (Fig. 14d). It might be possible that other forms of expression, including $L_{g 85}$ and the length scaling the stratification at the base of ML, can match well with the observed MLD. But this issue is beyond the scope of this article and will be a subject in our further studies. Before more reasonable scales are proposed, the use of modified parameter $m_{0}$ for the KTN ML model is appropriate and practically effective in improving the MLD simulations using the bulk ML model.

\section{Summary}

Subject to the strong turbulence in the upper ocean, the temperature, salinity and other tracers are nearly homogenized within some range of depths, which is known as the ML. As the ML plays an important role in the climate system through its influences on SST, a realistic MLD simulation is of great importance in representing the vertical mixing processes and the air-sea interactions. The bulk ML model developed by Kraus, Turner and Niiler is designed for describing the MLD and its variation; it has been adopted widely by many ocean modeling for the representation of the vertical mixing processes. However, the simulations with the original KTN ML scheme produce the pronounced MLD biases. This is partly attributed to the uncertainties in representing the wind stirring effect, which is scaled by $m_{0}$; it is traditionally taken as a constant uniformly in space. In this study, we attempt to improve the MLD simulation by optimizing this parameter. Specifically, the parameter $m_{0}$ is estimated through its inverse calculation from the KTN bulk equation, Argo dataset and meteorological reanalysis data. For the given fields (e.g., the MLD, the simultaneous atmospheric forcing fields calculated from the reanalysis dataset), $m_{0}$ can be estimated from the KTN equation. It is illustrated that the $m_{0}$ is spatially and seasonally varying over the tropical Pacific. The derived $m_{0}$ fields are then implemented into an OGCM. Compared with the observations and the GODAS analyses, the MLD simulations in the OGCM with the spatially and seasonally varying $m_{0}$ are substantially improved in the tropical Pacific Ocean on seasonal and interannual time scales. Additionally, the STCs 
(a) Correlation between MLD and $\mathrm{u}_{*}$

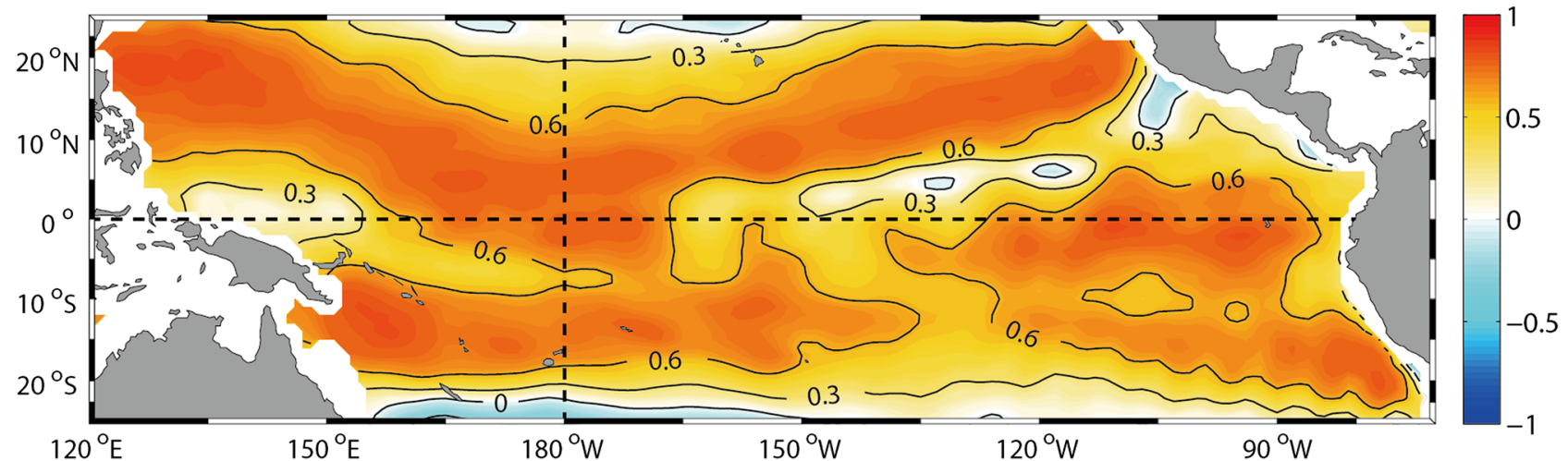

(b)

(c)

(d)
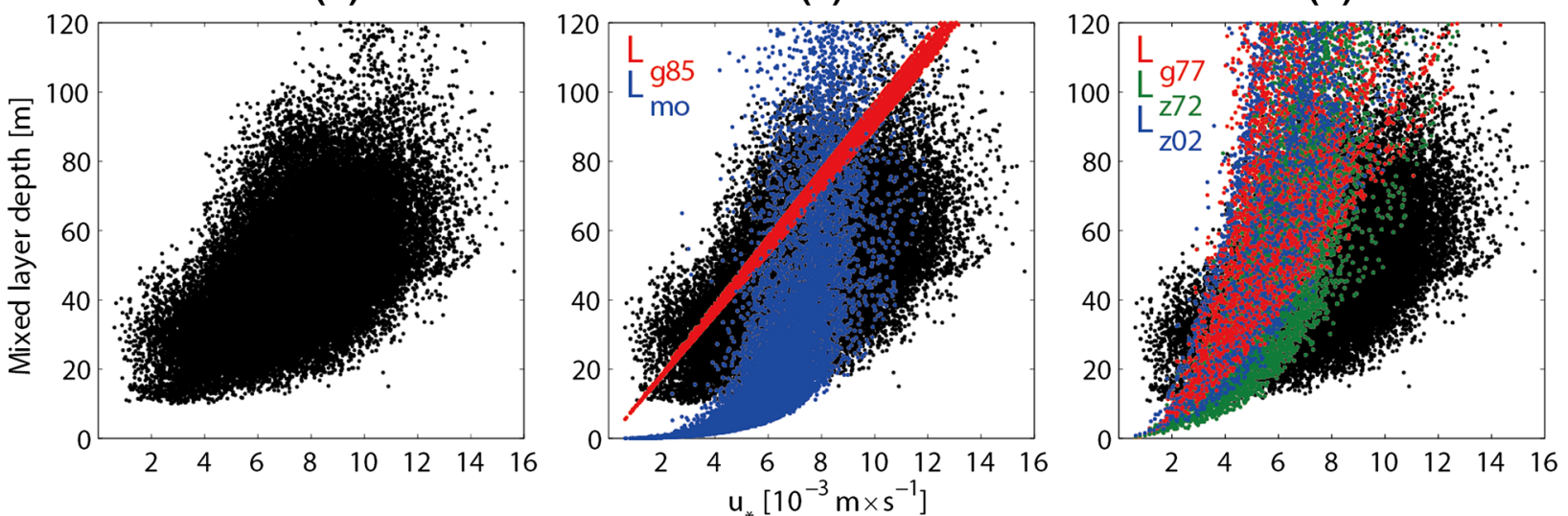

Fig. 14 a Correlation between the friction velocity $\left(u_{*}\right)$ and Argo MLD in the tropical Pacific during the period 2005-2015. b Scatterplot of the relationship between $u_{*}$ and Argo MLD with the correlation exceeding 0.6. $\mathbf{c}$ The same as in Fig. $14 \mathrm{~b}$ but with the $L_{\text {mo }}$ (blue

become intensified, accompanied with the strengthening of upwelling in the eastern equatorial Pacific, which is more realistic in the varying $m_{0}$ case compared with the constant $m_{0}$ case. As the related cooling effect from the upwelling is enhanced, the simulated SST is slightly cooled down in the eastern equatorial Pacific.

The fields of $m_{0}$ are prescribed in our model exercises, but it should be represented as a function of the atmospheric forcing, the Coriolis parameter and the ocean stratification. The existing length scales characterizing the MLD are far from desirable to fit the observations. It may be due to the absence of the $\tilde{f}$ effects and the inadequate combinations at the different length scales. Therefore, more detailed investigation for these relationships is needed, and will be presented in the future study.

At present, a large number of bulk ML models have been proposed, but many of them suffer from appropriate representations of the wind stirring-related parameters (e.g., $m_{0}$ ) scaling the TKE input from the wind effects. Indeed, large biases exist in depicting the MLD in ocean modeling. The scatters) and $L_{\mathrm{g} 85}$ (red scatters). d The same as in Fig. 14b but with the length scales derived from Eq. $6\left(L_{\mathrm{g} 77}\right.$, red scatters), Eq. $8\left(L_{\mathrm{z} 72}\right.$, green scatters) and Eq. $9\left(L_{\mathrm{zo} 02}\right.$, blue scatters $)$, respectively

approach we proposed in this work can be easily adopted in other ML modeling and improved simulations are expected.

Acknowledgements We wish to thank the anonymous reviewers for their insightful comments and constructive suggestions. This research is supported by the CAS Strategic Priority Project (the Western Pacific Ocean System; Grant Nos. XDA11010105, XDA11020306), the National Natural Science Foundation of China (NFSC; Grant Nos. 41690122(41690120), 41421005), and the Taishan Scholarship and Qingdao Innovative Program (Grant No. 13-CX-22).

Open Access This article is distributed under the terms of the Creative Commons Attribution 4.0 International License (http://creativecommons.org/licenses/by/4.0/), which permits unrestricted use, distribution, and reproduction in any medium, provided you give appropriate credit to the original author(s) and the source, provide a link to the Creative Commons license, and indicate if changes were made. 


\section{References}

Acreman DM, Jeffery CD (2007) The use of Argo for validation and tuning of mixed layer models. Ocean Model 19:53-69

Barnett TP, Latif M, Graham N, Flugel M, Pazan S, White W (1993) ENSO and ENSO-related predictability. Part I: prediction of equatorial pacific sea-surface temperature with a hybrid coupled ocean-atmosphere model. J Clim 6:1545-1566

Bjerknes J (1969) Atmospheric teleconnections from the equatorial Pacific. Mon Weather Rev 97:163-172

Cane MA, Zebiak SE (1985) A theory for El Niño and the southern oscillation. Science 228:1085-1087

Chen D, Rothstein LM, Busalacchi AJ (1994a) A hybrid vertical mixing scheme and its application to tropical ocean models. J Phys Oceanogr 24:2156-2179

Chen D, Busalacchi AJ, Rothstein LM (1994b) The roles of vertical mixing, solar-radiation, and wind stress in a model simulation of the sea surface temperature seasonal cycle in the tropical Pacific Ocean. J Geophys Res 99:20345-20359

Cheng L, Kitade Y (2014) Quantitative evaluation of turbulent mixing in the Central Equatorial Pacific. J Oceanogr 70:63-79

Davis RE, Deszoeke R, Niler P (1981) Variability in the upper ocean during MILE, part 2: modeling the mixed-layer response. Deep Sea Res 28:1453-1475

Ekman VW (1905) On the influence of the earth's rotation on oceancurrents. Ark Mat Astron Fys 2:1-52. https://jscholarship.library. jhu.edu/handle/1774.2/33989. Accessed 28 Feb 2017

Fernando HJS (1987) Comments on "wind direction and equilibrium mixed-layer depth: general theory". J Phys Oceanogr 17:169-170

Galperin B, Rosati A, Kantha LH, Mellor GL (1989) Modeling rotating stratified turbulent flows with application to oceanic mixed layers. J Phys Oceanogr 19:901-916

Garwood RW (1977) An oceanic mixed layer model capable of simulating cyclic states. J Phys Oceanogr 7:455-468

Garwood RW, Gallacher PC, Muller P (1985a) Wind direction and equilibrium mixed layer depth: general theory. J Phys Oceanogr 15:1325-1331

Garwood RW, Muller P, Gallacher PC (1985b) Wind direction and equilibrium mixed layer depth in the Tropical Pacific Ocean. J Phys Oceanogr 15:1332-1338

Gaspar P (1988) Modeling the seasonal cycle of the upper ocean. J Phys Oceanogr 18:161-180

Gent PR, Cane MA (1989) A reduced gravity, primitive equation model of the upper equatorial ocean. J Comput Phys 81:444-480

Gerkema T, Zimmerman JTF, Maas LRM, van Haren H (2008) Geophysical and astrophysical fluid dynamics beyond the traditional approximation. Rev Geophys 46:RG2004

Goddard L, Mason SJ, Zebiak SE, Ropelewski CF, Basher R, Cane MA (2001) Current approaches to seasonal-to-interannual climate predictions. Int J Climatol 21:1111-1152

Godfrey J, Schiller A (1997) Tests of mixed-layer schemes and surface boundary conditions in an Ocean General Circulation Model, using the IMET flux data set. CSIRO Division of Marine Research. https://doi.org/10.4225/08/585c17b8378c3. Accessed 11 May 2017

Goh G, Noh Y (2013) Influence of the Coriolis force on the formation of a seasonal thermocline. Ocean Dyn 63:1083-1092

Hazeleger W, Haarsma RJ (2005) Sensitivity of tropical Atlantic climate to mixing in a coupled ocean-atmosphere model. Clim Dyn 25:387-399

Heidt FD (1977) The growth of the mixed layer in a stratified fluid due to penetrative convection. Bound Layer Meteor 12:439-461
Huang RX, Huang CJ, Wang W (2007) Dynamical roles of mixed layer in regulating the meridional mass/heat fluxes. J Geophys Res 112:359-412

Huang B, Xue Y, Zhang D, Kumar A, McPhaden MJ (2010) The NCEP GODAS Ocean analysis of the Tropical Pacific mixed layer heat budget on seasonal to interannual time scales. J Clim 234901-4925

Johnson GC, Sloyan BM, Kessler WS, McTaggart KE (2002) Direct measurements of upper ocean currents and water properties across the tropical Pacific during the 1990s. Prog Oceanogr 52:31-61

Kalnay E et al (1996) The NCEP/NCAR 40-year reanalysis project. Bull Am Meteor Soc 77:437-471

Kang YJ, Noh Y, Yeh S-W (2010) Processes that influence the mixed layer deepening during winter in the North Pacific. J Geophys Res 115:C12004

Kara AB, Rochford PA, Hurlburt HE (2000) An optimal definition for ocean mixed layer depth. J Geophys Res 105:16803-16821

Kato H, Phillips O (1969) On the penetration of a turbulent layer into stratified fluid. J Fluid Mech 37:643-655

Kraus EB, Turner JS (1967) A one-dimensional model of the seasonal thermocline II. The general theory and its consequences. Tellus 19:98-106

Large WG, McWilliams JC, Doney SC (1994) Oceanic vertical mixing: a review and a model with a nonlocal boundary layer parameterization. Rev Geophys 32:363-403

Lee E, Noh Y, Qiu B, Yeh S-W (2015) Seasonal variation of the upper ocean responding to surface heating in the North Pacific. J Geophys Res 120:5631-5647

Liu Q, Lu Y (2016) Role of horizontal density advection in seasonal deepening of the mixed layer in the subtropical Southeast Pacific. Adv Atmos Sci 33:442-451

Liu Z, Philander SGH (2001) Chap. 4.4 tropical-extratropical oceanic exchange pathways. Int Geophys 77:247-257

Lorbacher K, Dommenget D, Niiler PP, Köhl A (2006) Ocean mixed layer depth: a subsurface proxy of ocean-atmosphere variability. J Geophys Res 111:C07010

Lozovatsky I, Figueroa M, Roget E, Fernando HJS, Shapovalov S (2005) Observations and scaling of the upper mixed layer in the North Atlantic. J Geophys Res 110:C05013

Maritorena S, d'Andon OHF, Mangin A, Siegel DA (2010) Merged satellite ocean color data products using a bio-optical model: Characteristics, benefits and issues. Remote Sens Environ 114:1791-1804

Martin PJ (1985) Simulation of the mixed layer at OWS November and Papa with several models. J Geophys Res 90:903-916

Mellor GL, Yamada T (1982) Development of a turbulence closuremodel for geophysical fluid problems. Rev Geophys 20:851-875

Murtugudde R, Seager R, Busalacchi A (1996) Simulation of the tropical oceans with an ocean GCM coupled to an atmospheric mixedlayer model. J Clim 9:1795-1815

Murtugudde R, Beauchamp J, McClain CR, Lewis M, Busalacchi AJ (2002) Effects of penetrative radiation on the upper tropical ocean circulation. J Clim 15:470-486

Niiler P, Kraus EB (1977) One-dimensional models of the upper ocean, modelling and prediction of the upper layers of the Ocean EB Kraus, 143-172, edited. Pergamon, New York

Noh Y, Goh G, Raasch S (2010) Examination of the mixed layer deepening process during convection using LES. J Phys Oceanogr 40:2189-2195

Pollard RT, Rhines PB, Thompson RORY (1972) The deepening of the wind-mixed layer. Geophys Fluid Dyn 4:381-404

Pookkandy B, Dommenget D, Klingaman N, Wales S, Chung C, Frauen C, Wolff H (2016) The role of local atmospheric forcing on the modulation of the ocean mixed layer depth in 
reanalyses and a coupled single column ocean model. Clim Dyn 47(9-10):2991-3010

Price JF, Weller RA, Pinkel R (1986) Diurnal cycling-observations and models of the upper ocean response to diurnal heating, cooling, and wind mixing. J Geophys Res 91:8411-8427

Resnyanskiy YD (1975) Parameterization of the integral turbulent energy dissipation in the upper quasi homogeneous layer of the ocean. Izv Atmos Ocean Phys 11:453-457

Rossby CG, Montgomery RB (1935) The layer of frictional influence in wind and ocean currents. Massachusetts Institute of Technology and Woods Hole Oceanographic Institution, p 101

Rothstein LM, Zhang R-H, Busalacchi AJ, Chen D (1998) A numerical simulation of the mean water pathways in the subtropical and Tropical Pacific Ocean. J Phys Oceanogr 28:322-343

Schopf PS, Cane MA (1983) On equatorial dynamics, mixed layer physics and sea surface temperature. J Phys Oceanogr 13:917-935

Seager R, Zebiak SE, Cane MA (1988) A model of the tropical pacific sea-surface temperature climatology. J Geophys Res 93:1265-1280

Sterl A, Kattenberg A (1994) Embedding a mixed-layer model into an ocean general-circulation model of the Atlantic - the importance of surface mixing for heat-flux and temperature. J Geophys Res 99:14139-14157

Wang D (2003) Entrainment laws and a bulk mixed layer model of rotating convection derived from large-eddy simulations. Geophys Res Lett 30(18):1929. https://doi.org/10.1029/2003GL017869

Yoshikawa Y (2015) Scaling surface mixing/mixed layer depth under stabilizing buoyancy flux. J Phys Oceanogr 45:247-258

Zebiak SE, Cane MA (1987) A model El Niño/Southern oscillation. Mon Weather Rev 115:2262-2278

Zhang R-H (2015) An ocean-biology-induced negative feedback on ENSO as derived from a hybrid coupled model of the tropical Pacific. J Geophys Res 120:8052-8076
Zhang R-H, Levitus S (1996) Structure and evolution of interannual variability of the Tropical Pacific upper ocean temperature. J Geophys Res 101:20501-20524

Zhang R-H, Zebiak SE (2002) Effect of penetrating momentum flux over the surface boundary/mixed layer in a z-coordinate OGCM of the Tropical Pacific. J Phys Oceanogr 32:3616-3637

Zhang R-H, Rothstein LM, Busalacchi AJ (1998) Origin of upperocean warming and El Nino change on decadal time scales in the Tropical Pacific Ocean. Nature 391:879-883

Zhang R-H, Busalacchi AJ, Murtugudde RG (2006) Improving SST anomaly simulations in a layer ocean model with an embedded entrainment temperature submodel. J Clim 19:4638-4663

Zhang R-H, Chen D, Wang G (2011) Using Satellite ocean color data to derive an empirical model for the penetration depth of solar radiation (H-p) in the Tropical Pacific Ocean. J Atmos Ocean Technol 28:944-965

Zhang R-H, Gao C, Kang X, Zhi H, Wang Z, Feng L (2015) ENSO modulations due to interannual variability of freshwater forcing and ocean biology-induced heating in the tropical Pacific. Sci Rep 5:18506. https://doi.org/10.1038/srep18506

Zhu J, Kumar A, Wang H, Huang B (2015) Sea surface temperature predictions in NCEP CFSv2 using a simple ocean initialization scheme. Mon Weather Rev 143:3176-3191

Zilitinkevich SS (1972) On the determination of the height of the Ekman boundary layer. Bound Layer Meteor 3:141-145

Zilitinkevich SS, Esau IN (2002) On integral measures of the neutral barotropic planetary boundary layer. Bound Layer Meteor 104:371-379 